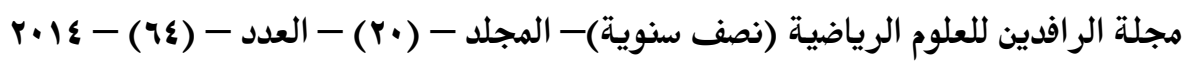

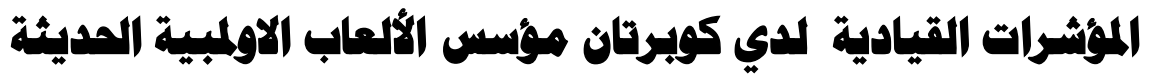

$$
\begin{aligned}
& \text { أ.م.د. رياض احمد إسماعيل" } \\
& \text { "فرع العوم الرياضية/كلية التربية الرياضية/جامعة الموصل/العرل//البريد الالكتروني: yahoo.comayel@yahom }
\end{aligned}
$$

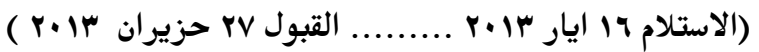

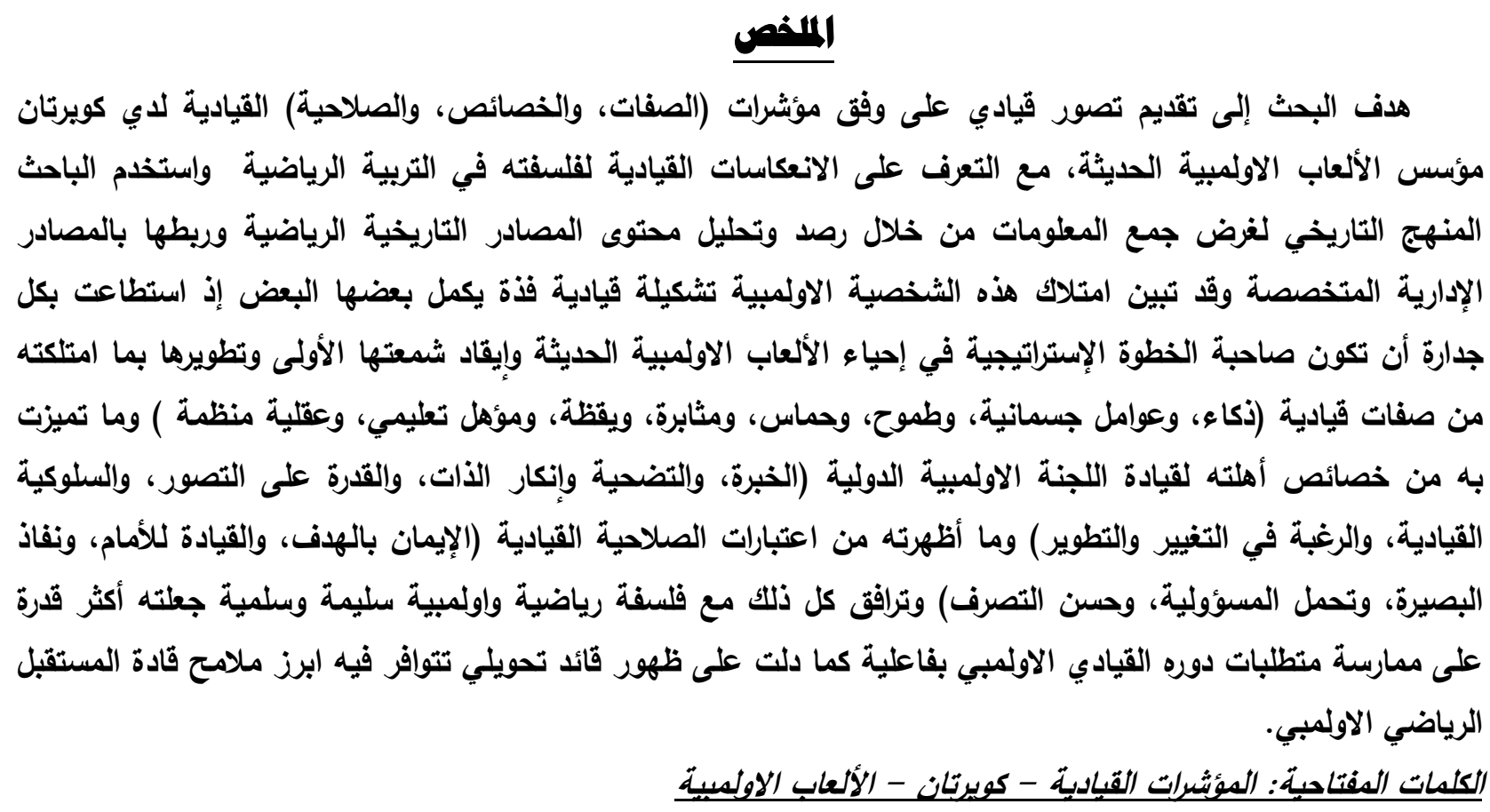

\title{
Leading Indicators of De Cobertan The Founder of Modern Olympic Games
}

Asst. Prof.Dr. Reyadh A. Ismaeel

\begin{abstract}
The research aims to present leading image according to leading indicators of De Cobertan the founder of modern Olympic games ( features, characters and validity), and introducing leading reflections for his philosophy in physical education, the researcher used historical method for collecting the information through analyzing the contents of sport history and connecting it with the special administration resources, and it becomes clear that this Olympic character had great leading frame and it complete each other, and it could be the first step in the strategy of reviving modern Olympic games and lightening its first candle and improving it and what it had of leading features ( intelligence, body factors, ambition, enthusiasm , hardworking, consciousness, educational qualification and organized mentality) and the characteristics it had that it prepare it to lead the international Olympic committee(experience, self- sacrifice, imagination ability, leading behavior, the desire of improvement and changing ), and it presents leading validity considerations ( aim faithing, forward leading, sight piercing , responsibility bearing and good behavior). and all that were accompanied with a correct Olympic sport philosophy and its correctness make it more able to practice the equipment of Olympic course effectively, and also it refers to produce conversion leader who have the most prominent future leader features .
\end{abstract}

Keywords: Leading Indicators - De Cobertan - Olympic Games 
تعيش الرياضة الاولمبية العالمية في تقدم وازدهار بمجالاتها الإدارية والتنظيمية والرياضية كافة وهو ما انعكس

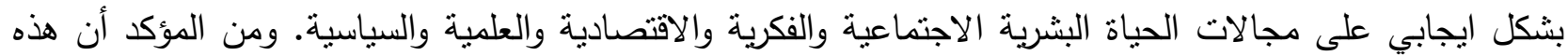
المدخلات والعمليات والمخرجات الاولمبية لم تأتي وليدة الحال الحاضر دفعة واحدة وما كانت لتصل إلى ما وصلت إليه لولا جهود قياداتها الرياضية وسيما الأوائل منهم والذين شكلوا نماذج إنسانية تستحق بما بذلته من جهود تطوعية

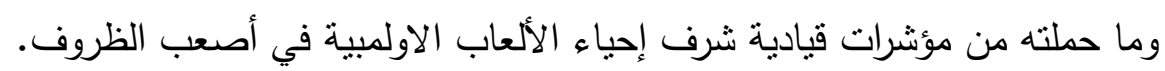
ويبرز من بين تلك القيادات البارون الفرنسي دي كوبرتان الذي يعد بحق أول من نذاتئ نذرة نفسه بكل ما يستطيع ليمهر الطريق الرياضي الاولمبي نحو أهدافه الإنسانية السامية. إذ تشكل حياته بمختلف جوانبها العلمية والفكرية والسلوكية والثقافية دروسا ينبغي الاستفادة منها بعد تحليلها وتحديد قدراتها القيادية لتعميمها على الملاكات الرياضية، إذ يؤدي الإي تحديد هذه المؤشرات القيادية والتعريف بها دورا حيويا في تفعيل تطبيقها لدى العاملين في إدارة المجال الرياضي أو الراغبين بذلك من خلال زيادة تصورهم وإدراكهم بما تميزت به إحدى أهم الثخصيات الرياضية والمؤثرة في قيادة الحركة الاولمبية الرياضية الحديثة. هذا على الرغم من أن مرحلة القيادة الفردية قد انتهت وانتقلت إلى العمل القيادي لهي الجماعي فإن ذلك لا يعني أبدا تجاوز قيمة القيادة الفردية بل أصبح مطلوبا من كل قائد (ومنهم الرياضي) أنس أن تتوافر

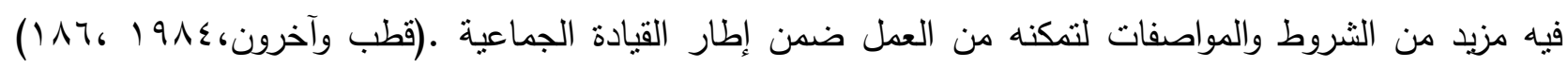
عليه تبرز أهمية البحث من منطلقين الأول انه يعد خطوة بداية لوضع تصور أولي حول بعض المؤشرات القيادية لمؤسس الحركة الاولمبية الحديثة (دي كوبرتان ) وبما يفتح المجال أمام بحوث ودراسات مكملة لهذه الثخصية الاولمبية أو غيرها من الثخصيات القيادية الرياضية، أما المنطلق الثاني فيكمن في أحداث خطوة من خطوات التكامل والتعثيق العلمي والعملي بين اختصاصي الإدارة الرياضية وتاريخ وفلسفة التربية الرياضية من خلال انموذج فلسفة التية (دي كوبرتان) في التربية الرياضية وانعكاساتها القيادية.

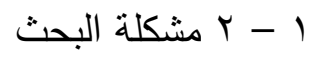

إن إحياء الحركة الاولمبية الحديثة وتطورها احتاج إلى العديد من الجهود والإمكانات التي تطلب إدارتها وتتظيمها قيادات ذات صفات ومؤهلات علمية وفكرية وسلوكية واجتماعية. ويأتي دي كوبرتان في مقدمة هذه القيادات فهو

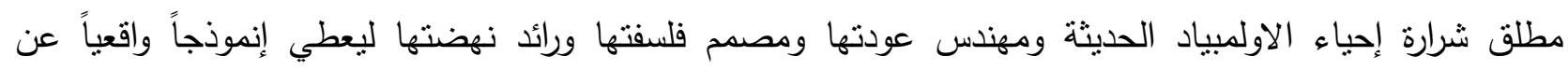
القيادات الرياضية الفعالة التي كافحت وضحت من أجل إرساء أسس ومبادئ وأفكار التحول والتغيير الواعي والمنظم في مجرى الحركة الرياضية العالمية. ومن هنا تظهر مشكلة البحث انه على الرغم مما تمتلكه هذه الثخصية الاولمبية الرائدة من إمكانات وصفات وفلسفة قيادية إلا أننا نلاحظ إغفال المصادر العلمية المتخصصة في مجالي الإدارة الرياضية وفلسفة وتاريخ التربية الرياضية تتاول هذه الكفاءة البشرية على وفق تصور فيادي واضح ومنظم هذا فضلاً عن عدم وجود دراسة علمية تحلل وتبين المؤثرات القيادية لشخصية (دي كوبرتان) كمثال حي للقيادة الرياضية البارزة للاستدلال بها كدليل عمل ينير طريق العاملين في إدارة المؤسسات الرياضية والراغبين في العمل الإداري الرياضي. r -

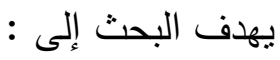
ا- تقديم تصور قيادي على وفق مؤشرات (الصفات، والخصائص، والصلاحية القيادية) لاي كوبرتان مؤسس الحركة 
ا- يمتلك (دي كوبرتان ) صفات وخصائص واعتبارات الصلاحية القيادية الرياضية أهلته لإحياء الألعاب الاولمبية الحديثة وإدارة تطويرها.

r- يحمل (دي كوبرتان) فلسفة رياضية واولمبية مكنته من القيام بدوره القيادي الرياضي والاولمبي بفاعلية. 1-0 - 1 مجالات البحث 1-ه-1 المجال البشري :- البارون الفرنسي (دي كوبرتان) مؤسس الألعاب الاولمبية الحديثة. r - 1

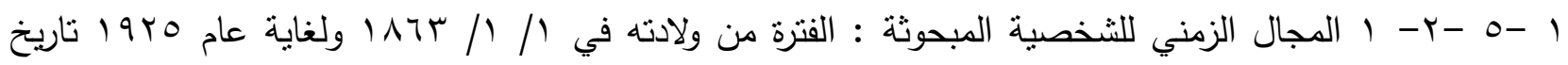
استقالته من رئاسة اللجنة الاولمبية الدولية

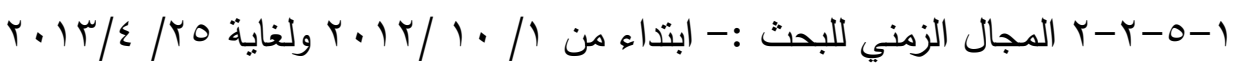

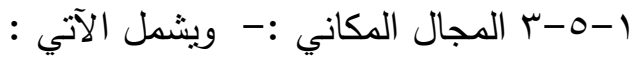

1-ه-r-1 المجال المكاني للشخصية المبحوثة : - دول متعددة وفقا لاماكن الأنشطة التي قام بها (دي كوبرتان)

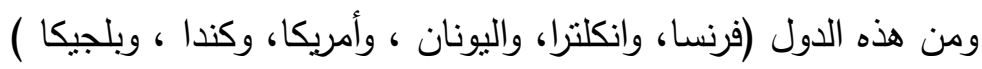

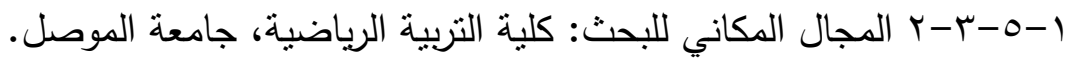
1-7 مصطلحات البحث 1-1-1 المؤشرات القيادية

يعرفها الباحث إجرائياً بأنها مجموعة من الدلائل والسلوكيات التي تشير إلى امتلاك الفرد لصفات وخصائص واعتبارات

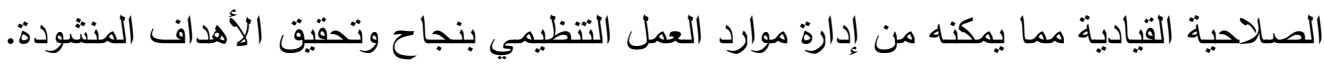

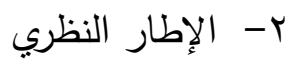
r- القيادة والقيادة الرياضية تعد القيادة عملية حيوية لازمة لعمل المنظمات والجماعات كافة وهي من أهم أسس المحافظة على مواردها وتتميتها وتقدمها المستمر • ويعد القائد الركن الأساس في العملية القيادية، فهي من إخراجه وأسمى نشاطاته التنظيمية. فالقائد

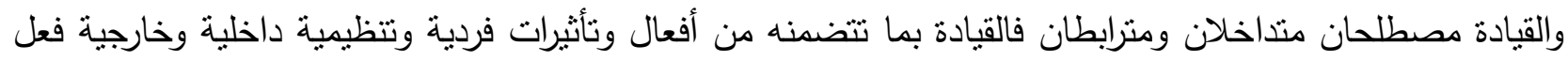
ومخرجات والقائد فاعل له الأمر الذي جعل معظم تعاريف القيادة تركز على التفاعل والمشاركة والتعاون والتأثثر المنبادل بين القائد والمرؤسين. استتادا إلى أن القيادة جهر وعمل يؤثر في الأفراد ويجعلهم يتعاونون لتحقيق هدف

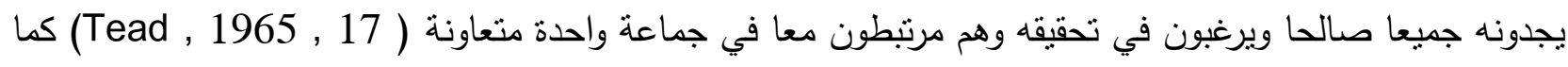
أنها القدرة التي يملكها الثخص في التأثثر على سلوك وأفكار ومشاعر العاملين من خلال حفزهم على تحقيق أهداف المنظمة ( Turban \& wtherbe,2002, 138 كما تعرف بأنها القدرة في التأثنر في الآخرين واستثمار جهودهم وتوجيه سلوكهم نحو تحقيق أهداف مشتركة (Browne \&Muth , 2004) وفي تصور متطابق تعرف القيادة الرياضية بأنها العملية التي يقوم فرد من أفراد جماعة رياضية منظمة بتوجيه سلوك الأفراد الرياضيين آو الأعضاء المنظمين للجماعات الرياضية من أجل دفعهم برغبة صادقة نحو تحقيق هدف مشترك بينهم ( علاوي ، 1919 ( 19 ، 17 ) r-1 - 1- مؤشرات القيادة الرياضية تعد القيادة الرياضية من العوامل المهمة ذات الأثر الكبير في حركية الجماعة ونشاط المنظمة وفي خلق التفاعل الإنساني اللازم لتحقيق أهداف الفرد أو المنظمة على حد سواء، ويكمن جوهر العملية القيادية في قدرات الفرد الذاتية 
التي يخلق من خلالها تأثيرا في سلوك ومشاعر المرؤوسين من خلال دوره بوصفه قائدا لهم ( العبدلي ، 1 ... ب ، (1) ولما كان مضمون القيادة يتمنل فيما يملكه القائد من مميزات وقدرات ترتكز على الفهم الصحيح والتفهم لكل اعتبارات

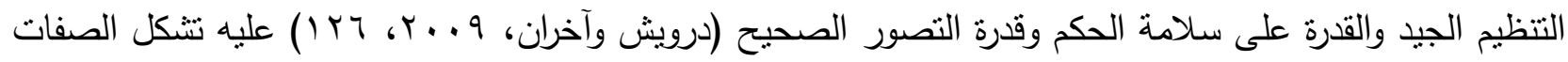
والخصائص واعتبارات الصلاحية من أهم قدرات القائد الذاتية وتشكل مؤشرات مهمة تزيد من احتمال ظهور قيادي

ناجح.

r-1-1-1 الصفات القيادية

تعرف الصفات القيادية بأنها مجموعة من الصفات لابد للقائد في المجال الرياضي أن بتصف بها حتى بينطيع أن

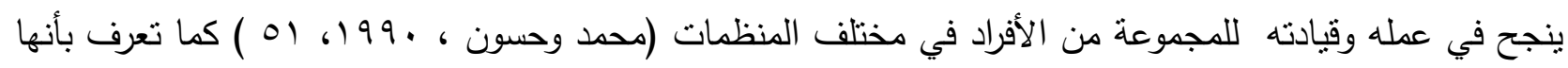

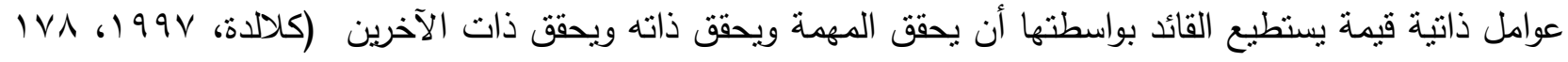

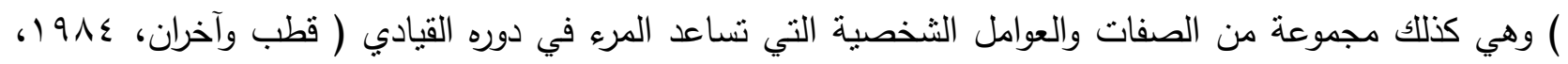

وعليه تؤدي هذه الصفات دوراً مهماً في عملية القيادة وتسهيلها؛ لذا يذكر أن القيادة تعتمد على الصفات الثخصية

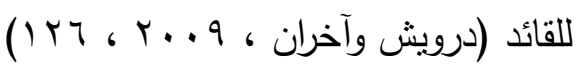
ونظر لوجود متغيرات عدة نؤدي دوراً مؤثراً في تحديد الصفات القيادية عليه طرحت المصادر المتخصصة التهان العامة

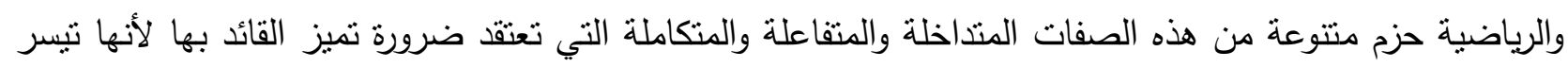

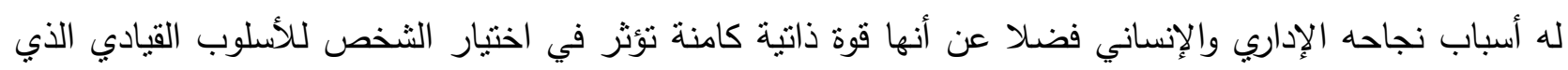

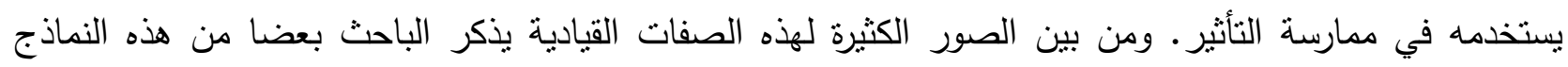
وكالآتي :- بلغنه

- أنموذج صفات القيادة عند (شلتوت ومعوض ، Y r 191 ، V0) و يتضمن :-

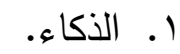
r.

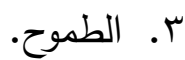

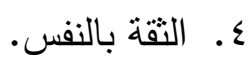
๑. حسم الأمور (اتخاذ القرارات) . لَ.

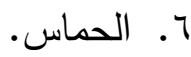
V. الروح العالية المتجددة.

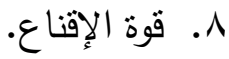

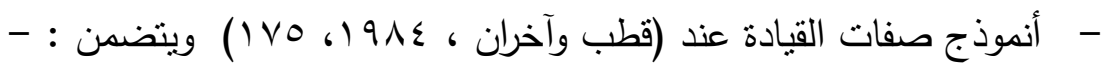

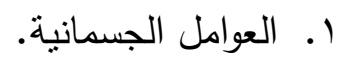

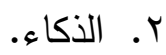

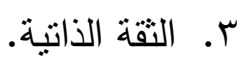

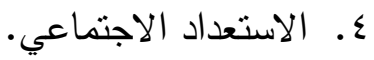
ه. الإرادة ( المبادرة، والمثابرة، و الطموح ). 7. V. المزاج (البشاشة، والحماس، واليقظة، والابتكار ). 
-

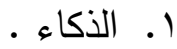

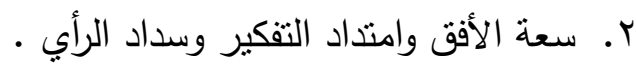

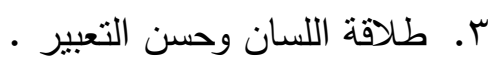
ع. الاتزان العاطفي والنضج العقلي و التحليل المنطقي .

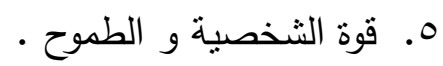

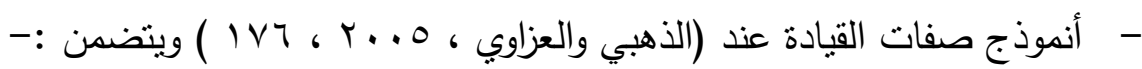

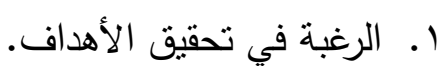

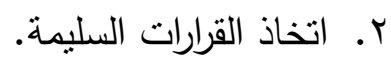
ب. الإنمان بالعلاقات الإنسانية. ع. الحماس والرغبة في العمل لتحقيق الهدف المنشود. الإنان.

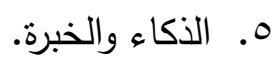
r-1-1-1 r-1 الخصائص القبادية

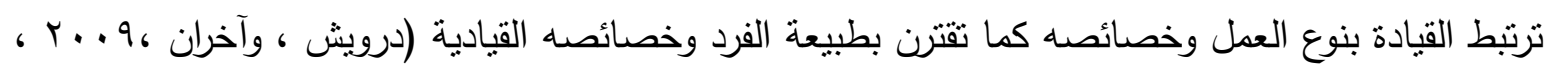

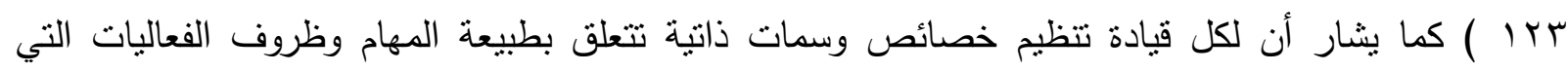

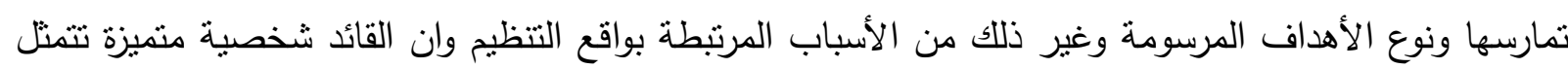

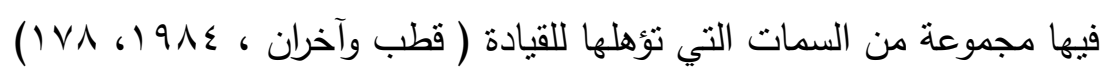
عليه تعرف الخصائص القيادية بأنها وظيفة من وظائف السمات والخصائص المكتسبة بالخبرة والتعلم التي يمكن

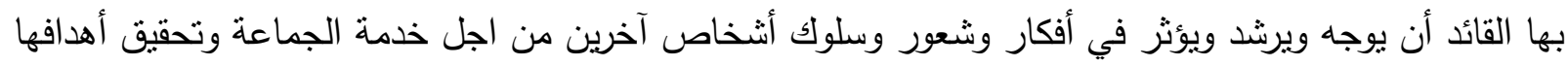

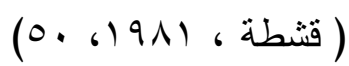

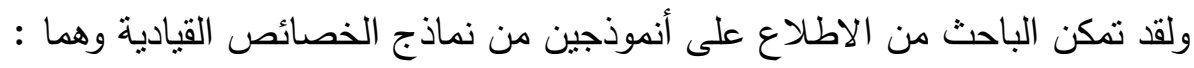

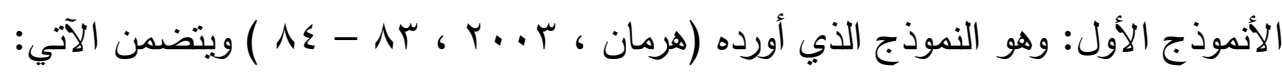

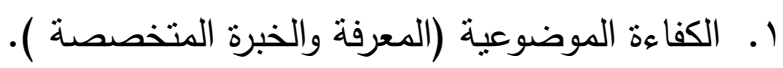
r. القارة على التتسيق.

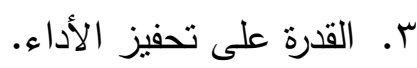
ع. القدرة على التمييز (الروئية الثاملة).

الأنموذج الثاني: هو الأنموذج الذي أورده (قطب وآخران، ع 19 19 ، IVA - . 19 ) ويتضمن الخصائص الآتية :

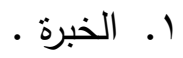
r. r. التضحية وإنكار الذات.

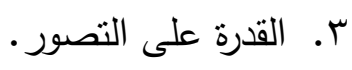
ع. السلوكية القيادية. 0. الرغبة في التغيير والنطور. ويعتقد الباحث أن الأنموذج الثاني يتضمن بصورة أو بأخرى الأنموذج الأول فضلا عن شموله على تصور نظري واضح يعين على رصد وتحليل جزئياته. 
r-1-1-1 الصلاحية القيادية

إنها مجموعة من الاعتبارات المطلوب توفرها في القائد الإداري وتدل على صلاحيته لقيادة العمل والتأثير الايجابي في مدخلاته وعملياته ومخرجاته من خلال أفكار ورؤى وسلوكيات تمكنه من العمل بمستوى المسؤولية الملقاة على العى

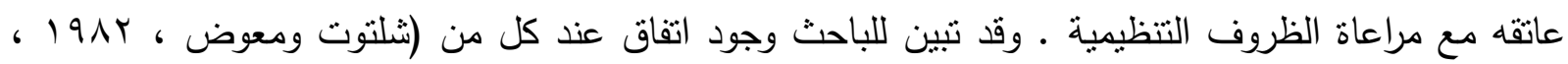

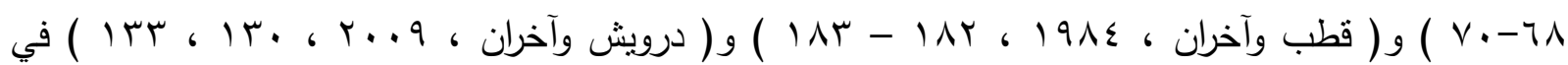
تحديد اعتبارات الصلاحية القيادية وكالاتي: ا ـ ـ تقهمه للأهداف العامة للاولة. r. الإيمان بالهذف.

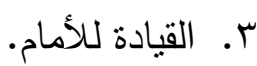
ع. نفاذ البصيرة. 0. تحمل المسؤولية. 7. التصرف على مستوى القيادة. V. حسن التصرف.

A. مراعاة العلاقات الإنسانية. 9. القيادة في اتجاه الإصلاح الإداري.

r-r دي كوبرتان وقيادة الحركة الاولمبية الحديثة

تشكل اللجنة الاولمبية الدولية أعظم منظمة اجتماعية تعنى بشؤون الرياضة التتافسية بين بلدان العالم المختلفة ، ولقد شهد هذا التظيم العالمي مواقف وتغيرات ونقلات حيوية عدة على مر التاريخ الاولمبي الحديث. كان من

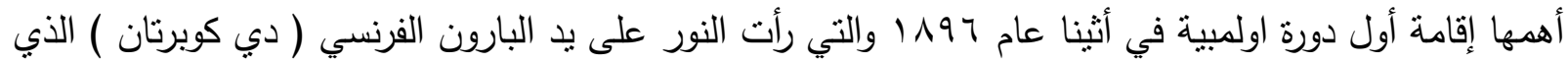

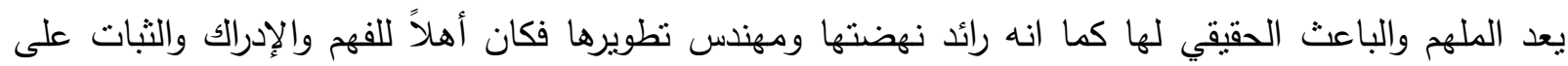

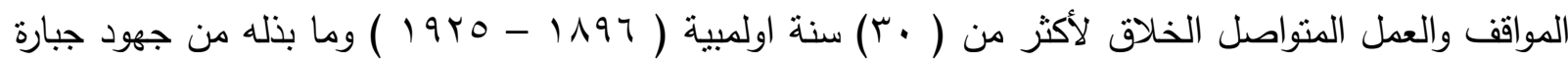

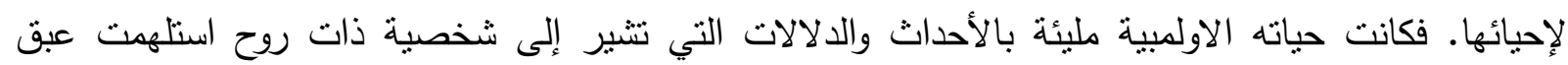
الماضي الرياضي لتنثره بحكمة ولباقة وحياد على واقع عاشته بكل جوارحها ليفتح ويفسح مجال التطور والإبداع في المستقبل الاولمبي فاستطاعت بكل جدارة أن تكون صاحبة الخطوة الإستراتيجية في إيقاد الثمعة الأولى وهي للألعاب الاولمبية الحديثة وتطويرها، الأمر الذي يؤكد أن المجال الرياضي يعد من أولى المجالات الحياتية التي يمكن من خلالها استثمار وتعزيز القدرات القيادية.

$$
\text { r- إجراءات البحث }
$$

استخدم الباحث المنهج التاريخي لملائمته لطبيعة البحث وأهدافه، إذ إن البحوث التاريخية نساعد الباحثين على تصور سيناريو مستقبلي بناءً على الأحداث الماضية وتقهمها فالتاريخ سجل لمنجزات الإنسان وليس مجرد سرد لأحداث زمنية

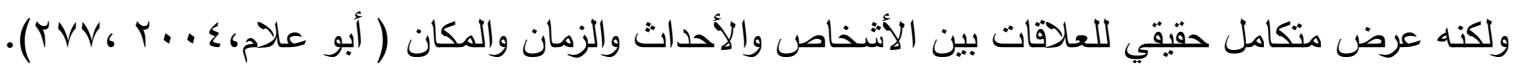


تم استخدام تحليل المتوى للمصادر والمراجع التاريخية المتعلقة بشخصية البحث من أجل الوصول إلى أهداف

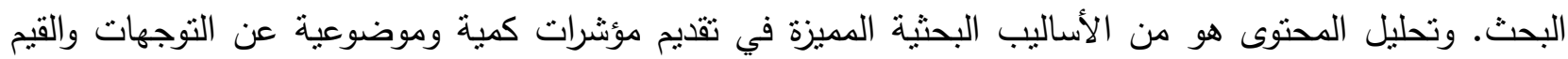

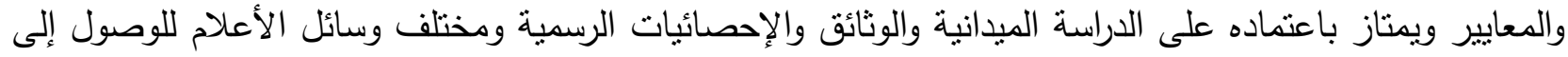

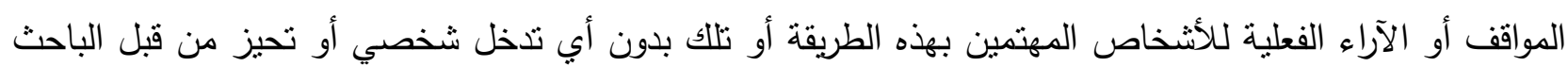

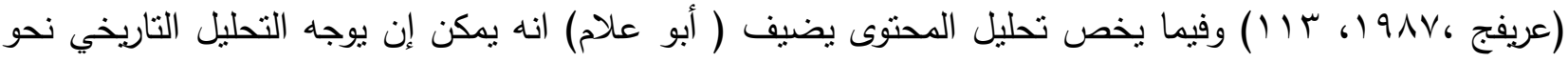

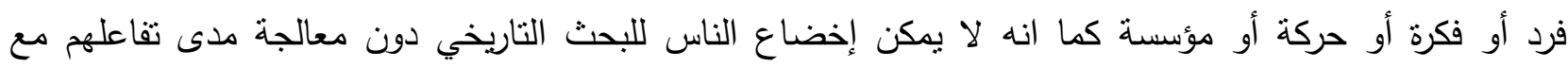

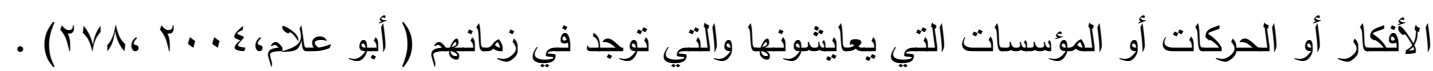

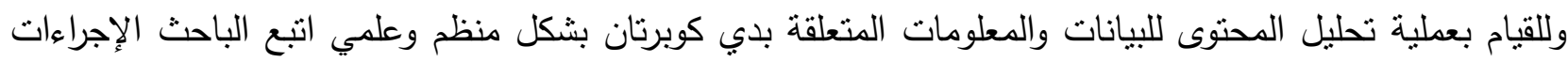

1- الإطلاع على العديد من المصادر الإدارية العامة والخاصة في المجال الرياضي لتحديد المؤشرات القيادية

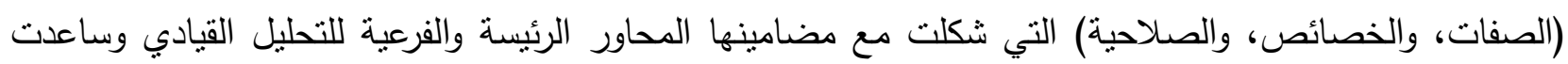
الباحث على وضع معايير موضوعية للقياس.

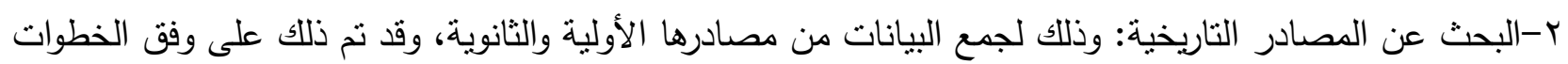

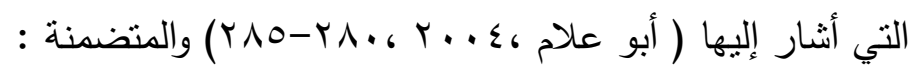

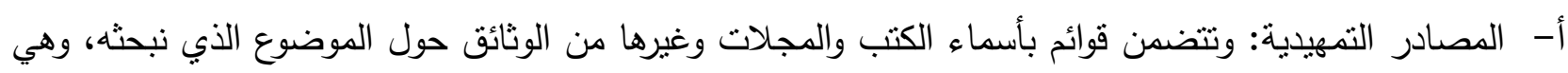

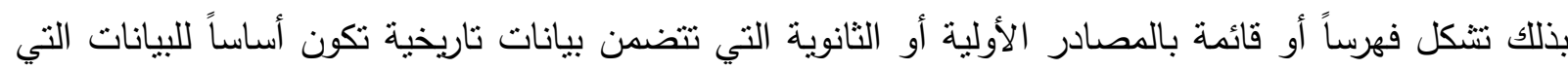

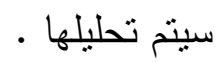

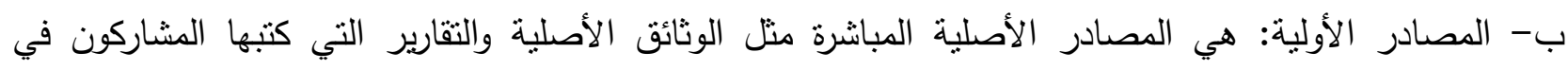

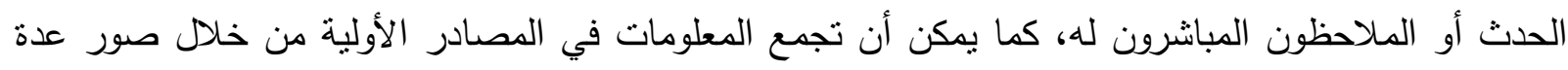

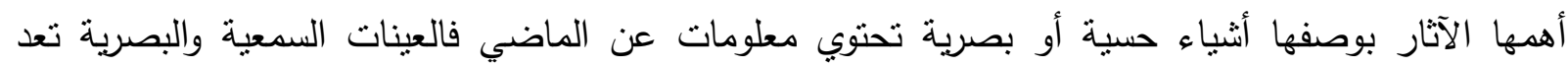

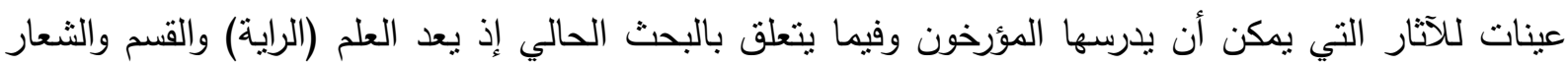

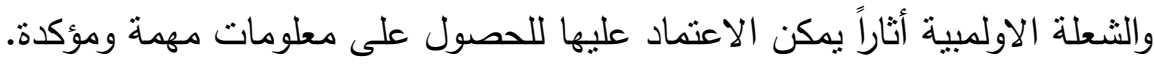

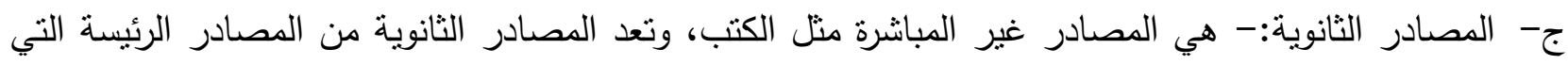
بستتد عليها الكثير من الباحثنين في المجال الناريخي.

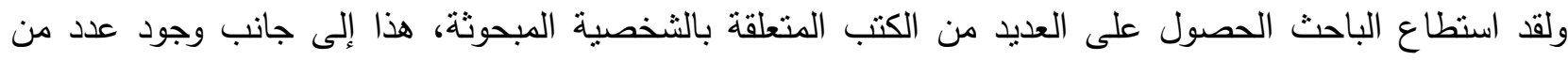

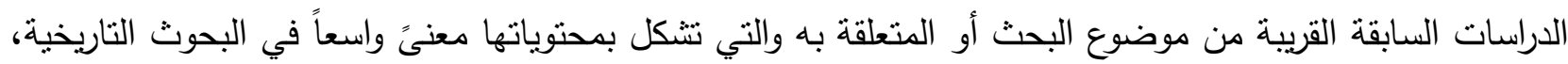
كما شكلت شبكة الدعلومات الدولية (الانترنيت) إحدى الوسائل المساعدة في تعزيز وتعميق الفهم ألمعلوماتي للثخصية التئية

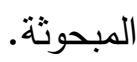
r- تصنيف المعلومات وتحديد الحقائق الثاريخية وتتظيمها على وفق المحاور الرئيسة والفرعية لمؤشرات القيادة،

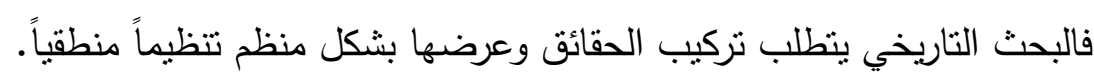
ع - معالجة البيانات :- إن معالجة البيانات في البحوث التاريخية عبارة عن تفسير البيانات التي يحصل عليها البانيا الباحث

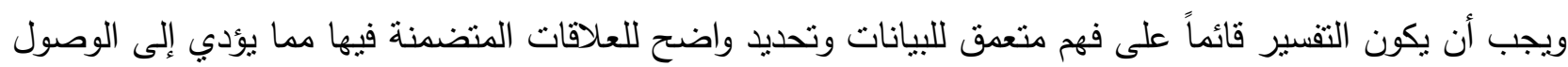

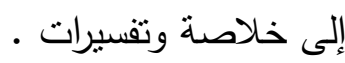


لقد أجمعت المصادر القيادية المتخصصة كافةً على الدور الأساس الذي تؤديه الصفات الثخصية للقائد في جودة أداءه الإداري، كما اتفقت هذه المصادر على وجود اختلاف في تحديد تلك الصفات تبعا لمتغيرات عدة فردية وتتظيمية وبيئية، عليه يذكر (درويش وآخران) انه لا يمكن أن نضع قائمة واحدة بالصفات والمميزات التي يجب أن تجنمع كلها

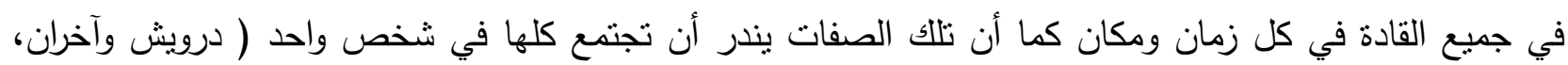

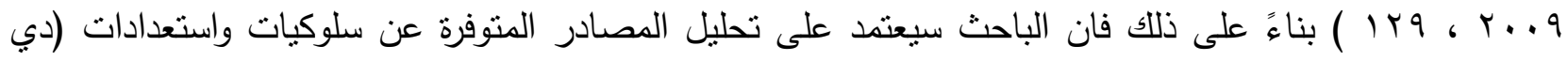
كوبرنان) من أجل وضع تصور أولي لما يتميز به من صفات قيادية وأهمها: ع- ا-1 الذكاء (ذكاء دي كوبرنان)

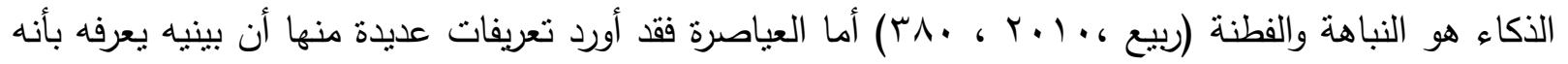

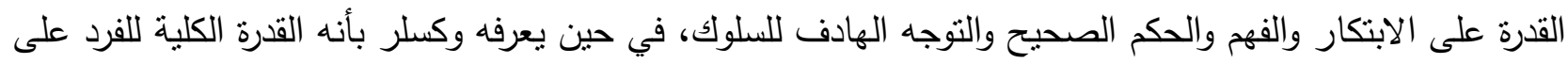
العمل الهادف والتفكير المنطقي والتقاعل الناجح مع البيئة، أما جودرد فيري أن الذكاء هو القدرة على الاستفادة من

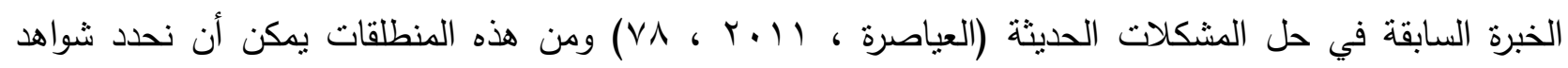
وملامح الذكاء عند (دي كوبرتان) إذ يذكر انه صاحب موهبة أصيلة ومنظمة قادته إلى تأسيس اللجنة الاولمبية الدولية

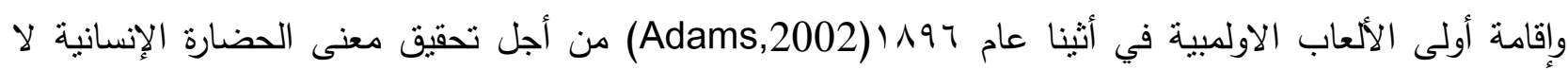

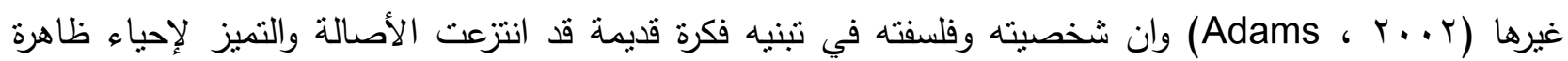
اجتماعية تاريخية وعالمية وبهذا العمل فان انجازه يعد تاريخيا بجعل حضارة جديدة تتبنى أفكارا لحضارة قديمة وتعدل من سلوكها وتبرمج نشاطاتها في ضوءها وكان بعطله هذا قد استلهم التاريخ من خلال فلسفة الرياضة وهو بذللك جعل العالم يحترم أفكاره وشخصيته العبقرية التي قادت المجتمعات العالمية إلى انتهاج منهجه في تبني الرياضة ومزاولتها

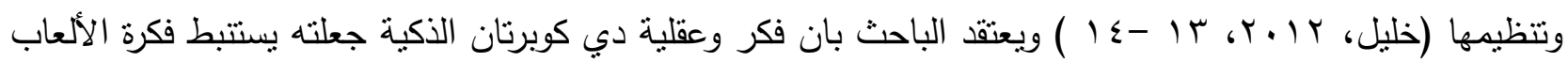
الاولمبية الثتوية من خلال استعراضات التزلج على الجليد التي كانت أيضا إحدى نتاجات عقليته إذ ادخل هذه

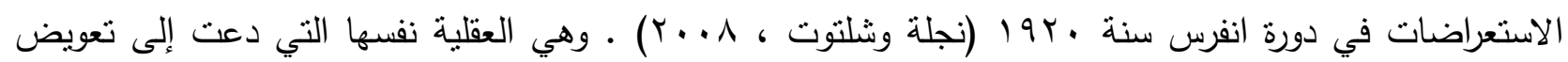

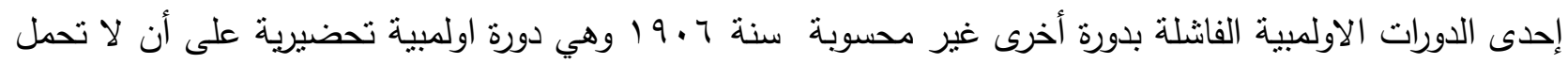
تسلسلا ضمن الدورات الاولمبية وذللك بسبب عدم إقامتها ضمن الفترة المحددة للدورات وأقيمت في أثثنا وكان لها ردود

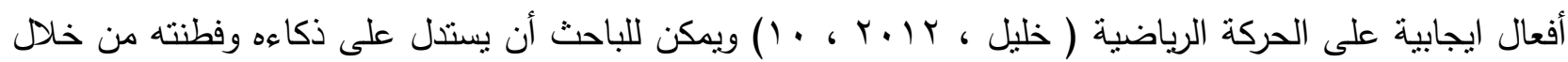
أمله في أن الألعاب الاولمبية سوف تغير المد الذي راءه في كل أنحاء العالم بما يخص نمو تجارة الرياضة http:Iteacher.schotlastic .comlactivites games \modern .htm. ومن خلال صورة أخرى للذكاء تتمثل في القدرة على تكوين المفاهيم وفهم دلالتها والقدرة على التفكير باستخدام الرموز

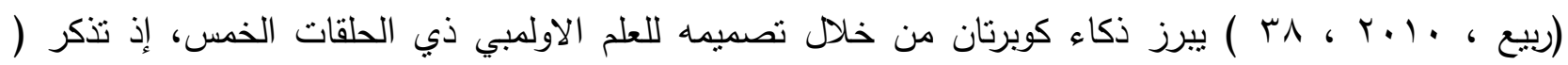

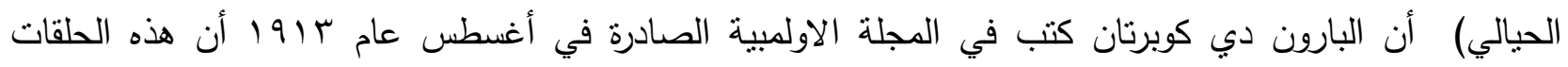

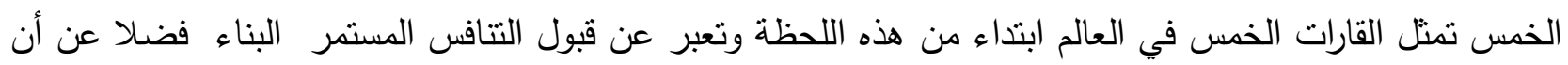

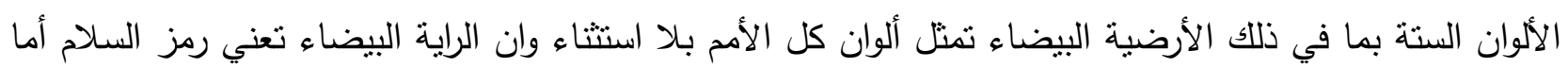

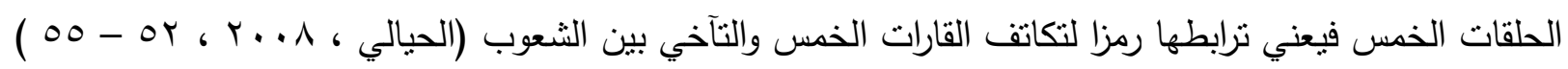

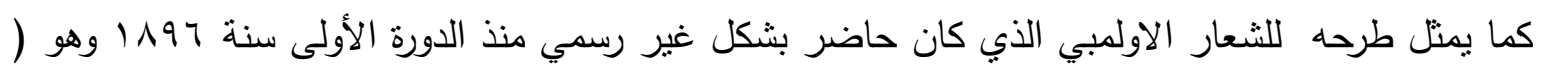

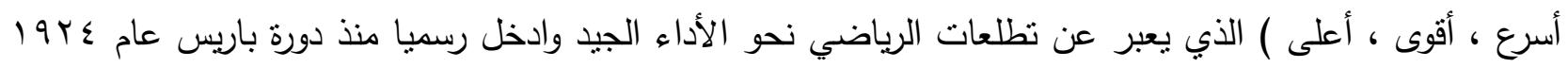


إذ تعود فكرة هذا الثعار لكوبرتان الذي أخذه (التقطه ) من صديقه الراهب الدومينكاني هنري ديدون (جاب الله، Y • Y ) كما يعد القسم الاولمبي من أهم طروحاته الذكية فقد كتب كلماته ونم ترديده رسميا لأول مرة في اولمبياد

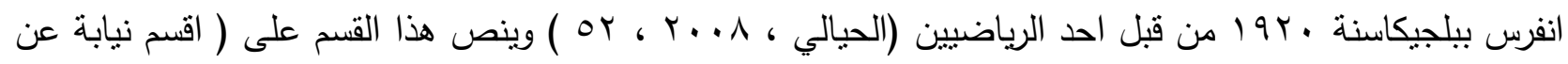
جميع الرياضيين أننا سنشارك في هذه الدورة الاولمبية بروح رياضية ونحترم ونلتزم بمختلف اللوائح والقواعد من أجل الجل

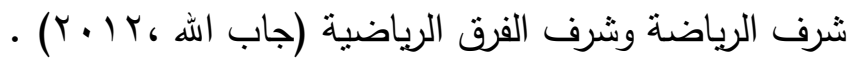
وفي صورة من صور الذكاء تتمثل في الذكاء الإداري الذي يعرف بأنه مجموعة القدرات التي تكفل لصاحبها إدارة

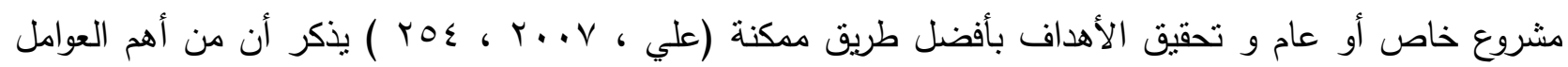
التي ساعدت على نجاح الحركة الاولمبية الأسلوب الذي اتبعه كوبرتان مؤسس الحركة إذ قام باختبار أعضاء اللجنة الدولية الأولى بنفسه وكان سبب اختبارهم على اعتبار أنهم يحملون وجهات نظر دولية فهم يمتازون بولائهم للمبادئ الاولمبية الدولية ولا يخضعون لأية ضغوط اقتصادية أو سياسية بحيث تحمل في طياتها عوامل استمرارها وكان ذلك بلك

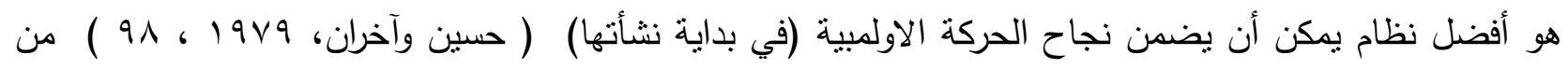
الثواهد السابقة يمكن للباحث أن يؤكد ذكاء دي كوبرتان الذي يعد من وجهة نظر (المغربي) من أهم صفات القيادة

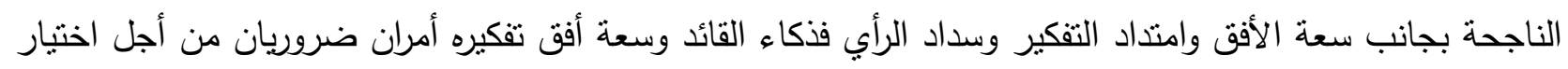

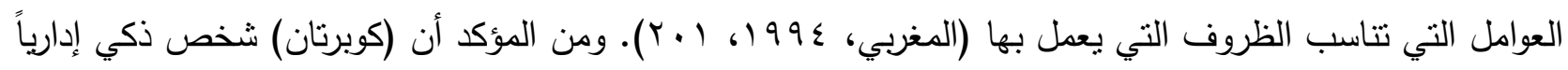

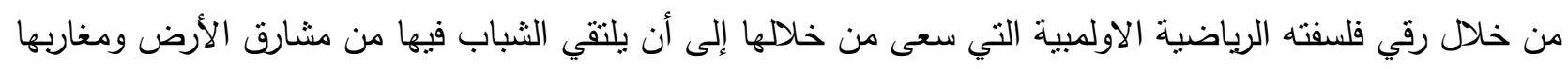
ليتعرف كل منهم على فكره وثقافة ولغة الآخر لتجمع الحضارات المختلفة لا فرق بين ابيض واسود ( جاب الله

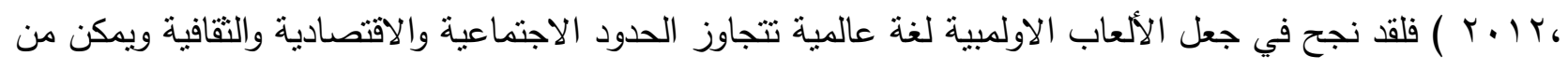

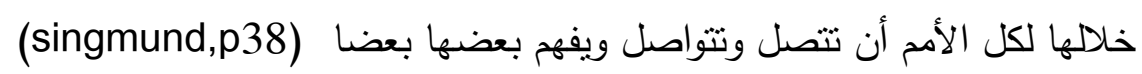

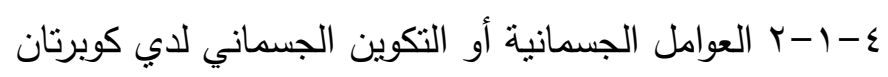
يمكن أن بسنتبط الباحث امتلاك دي كوبرتان لتكوين جسماني مناسب وجيد من خلال أمرين، الأول انه زاول العاب

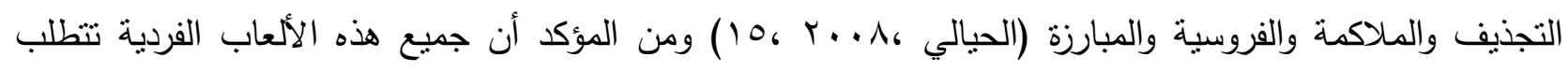

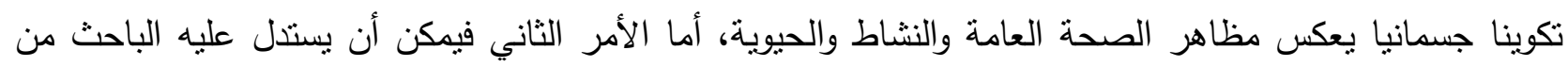

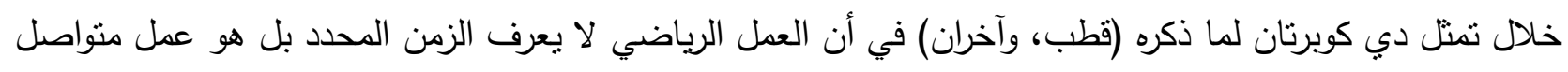

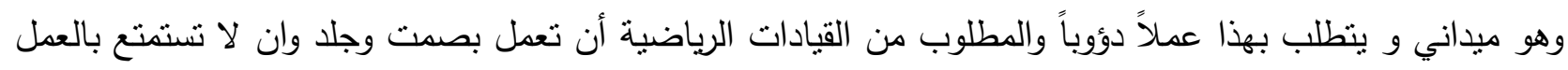
المكتبي والاجتماعات النظرية وتغيب عن الميادين والساحات و مواقع العمل المختلفة. (قطب وآخران ، عـ9 (، ـ 9 ( ) )

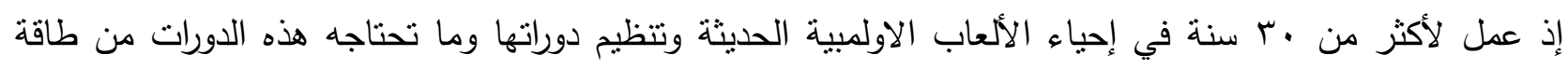
للتخطيط والإشراف والتوجيه والتطوير والتتقل لحضور الاجتماعات هذا فضلا عما بذله دي كوبرتان من جهود كبيرة قبل إقامة الاولمبياد الحديثة في زياراته العلمية والعملية ودراساته البحثية وحضوره للعديد من المؤتمرات في انكلترا

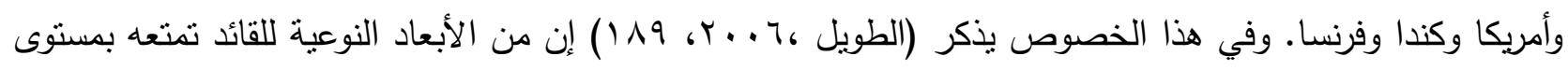
من الصحة الجسمية تمكنه من أن ينشط ويتحرك ويبذل الجهد الذي تتطلبه أدواره القيادية. ع يثير (قطب وآخران، ع^ه9 () إلى ضرورة اتصاف القائد بالثقة الذاتية والاستعداد الاجتماعي والطموح، من هذا الأساس يمكن أن يذكر البحث أن (كوبرتان) سعى في اثناعة طموحات ذاتية لكنها في غاية الجماعية والإنسانية بما يمتلكه من ثقة ذاتية تبلورت من خلال مصادر عدة ذاتية وعائلية وعلمية وحتى سياسية دعمته في حضور مؤتمرات وزيارات علمية داخل وخارج فرنسا وتكاملت هذه التقة بما توفر لديه من استعداد اجتماعي تبلور في تقديم خدماته التي لم 
تقتصر على بلده وإنما شملت العالم بأسره إذ توافقت أهدافه مع الأهداف العليا للمجتمع برمته وشموله في التعايش

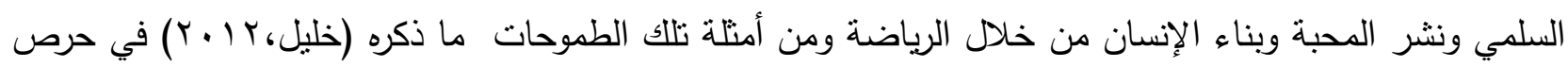
(كوبرتان) على أبعاد العنصرية والتعصب عن الألعاب الاولمبية وقد خاف أن نتهار فكرة الألعاب الاولمبية الحديثة بسبب الاحتراف؛ لذا اهتم بأبعادها عن الدورات الاولمبية والاهتمام بالهواية فقد كان طموحه إثترالك اكبر عدد من التهان

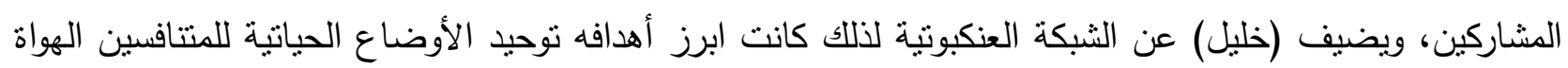
وتقريب الإنسان من الإنسان ثم جمع شباب العالم وهم عصب الحياة في هياكل الأمم في ميزان واحد ليتعارفوا ويتحابوا

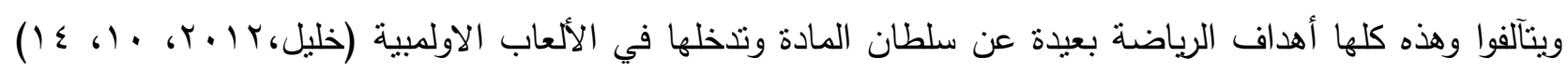
وفي هذا الصدد يذكر أن من أدق مهام القيادات الرياضية صهر جميع الثرائح الاجتماعية والتقافية المتعددة والمكونة

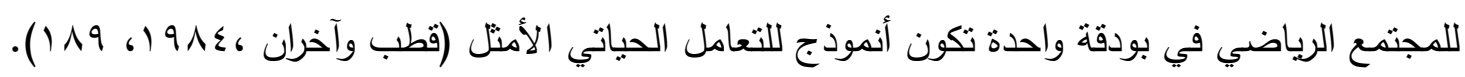
ومن وجه نظر طموحاته كان يرى أن الرياضة أسلوب من أساليب إعادة بناء مجد وطنه فرنسا وفي الوقت نفسي الونه هي إنشاء عالم سلمي وائتلافي يزرع الحب والسلام بين شعوب العالم من خلان اللقاءات الرياضية (Guttman,1992)

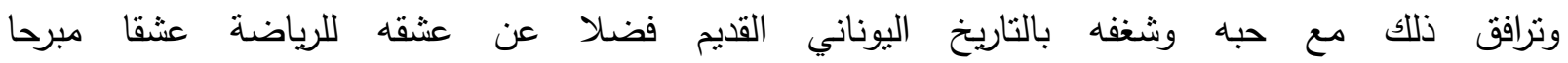
(http://ar.wikipedia.org) الرياضية عقيدة ومذهب ولاسيما أن الرياضي يشرف قومه وموطنه وعلمه راية بلده وإحياء الألعاب الاولمبية يعني إحياء التربية البدنية والسلوكية الصحيحة (www.alkass.net) بوصفها تصرفات تدل على مستوى عالي من الطموح للوصول بالرياضة الاولمبية إلى غاياتها الإنسانية السامية، وتتمثل هذه الغايات السامية كما ذكرها (السهروردي، • 19 1، Y 1 ) في تقريب وجهات النظر من خلال الألعاب وقوانينها وجعل الثباب على اختلاف مشاربهم يمارسون ألوانا من الألعاب الرياضية التي أمست ضرورة صحية واجتماعية من ضرورات الحياة المعاصرة . ع- -

إن القائد الرياضي الطموح يتميز بالمثابرة والإصرار وعدم فقد الأمل في تحقيق الهدف النهائي ولا بيتسلم بسهولة

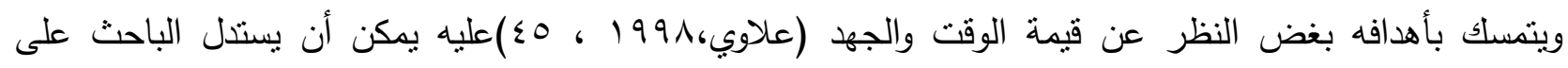
حماسه ومثابرة (دي كوبرتان) من خلال ذكر بعض تصرفاته المتعلقة بإحباء الألعاب الاولمبية وكالآتي:-

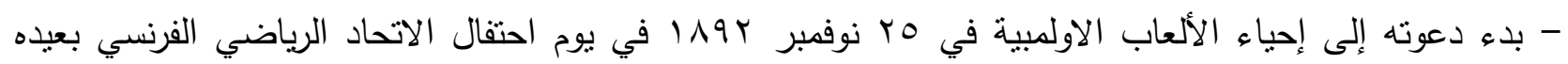

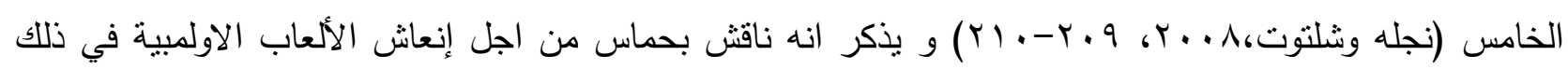
(kanin, 1982) (الاحتفال - على الرغم من وصف دعوته إلى إحياء الألعاب الاولمبية بالمبالغة والتي اعتبرت أنها مجرد حماسة شاب لابد أن

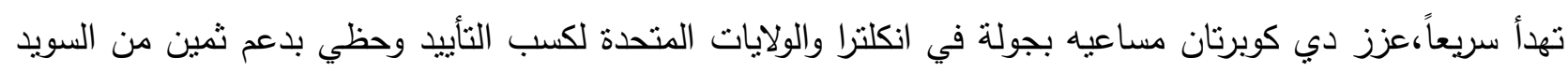

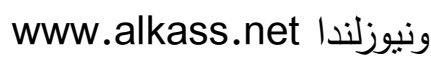
- سعى بما امتلك من علاقات بناها في سفرياته ومن قوة نفوذ داخل فرنسا لبلورة مؤتمر لطرح قضاياه بإطار عالمي

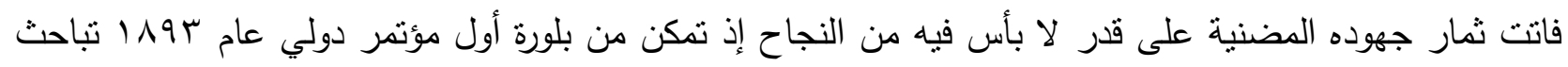

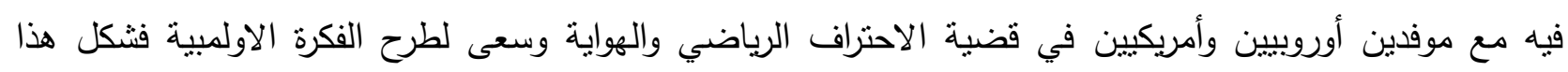

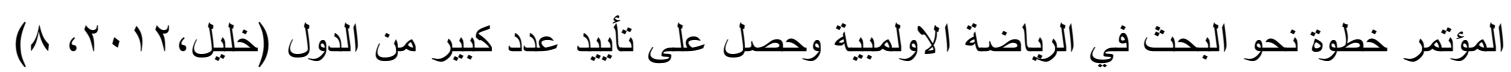

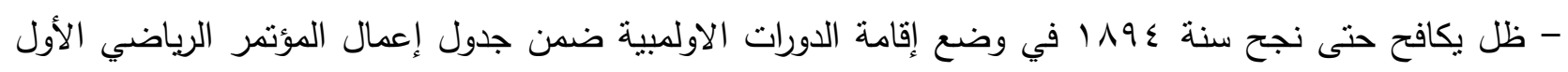
الدولي في السوربون فأثثرت الفكرة إذ تمت الموافقة على فكرة إقامة الألعاب الاولمبية الحديثة واختيرت أثنينا كمكان

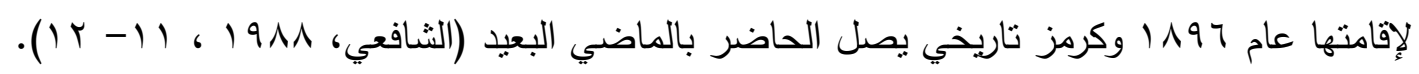


وفي هذا الصدد يذكر أن البارون دي كوبرتان خطط لإحياء الألعاب الاولمبية لفترة (1 (1) سنة (الخطيب والمشهداني ،

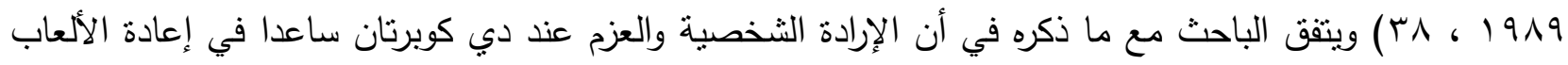

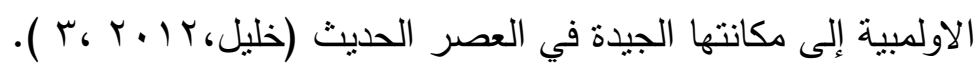
كما يمكن للباحث أن يستذل على حماسته ومثابرته أثناء أول دورة اولمبية إذ يذكر انه واجهت أولى الدورات

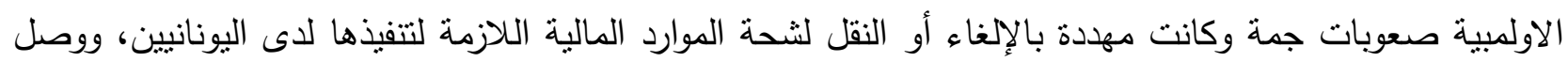
الأمر إلى حد البأس من أمكان نتظيمها وكان كوبرتان في هذا الوقت موجوداً في اليونان ساعياً بكل قدراته لإنجاح

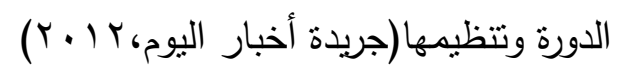
مما سبق يمكن للباحث أن يستتبط أن دي كوبرتان يمتلك صفات قيادية ذاتية مترابطة وصادقة تتم عن وجود إرادة شخصية قوية يعززها حماس منقطع النظير ومثابرة صابرة وعزيمة لا تلين،وفي هذا الصدد يذكر أن من أهم الخصائص والصفات التي يتميز بها الإداريون المتميزون انه لا يستسلم بسهولة وانه يتعامل مع متطلبات التغيير

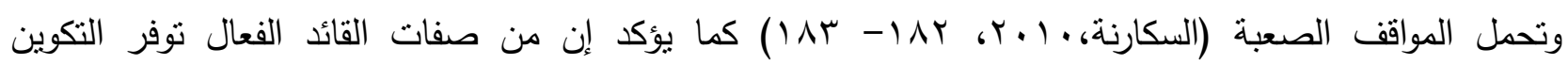

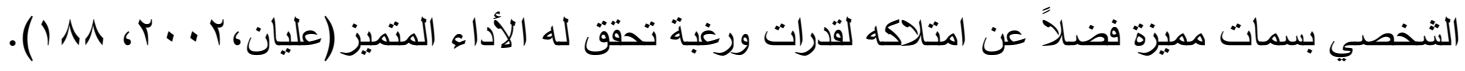
ع-1-

كان دي كوبرتان شخصية يقظة ذا انتباه مكنه من تفهم وإدراك الأحداث والقضايا التي عاصرها ليتعامل معها بجدية وإحساس قيادي من خلال طروحاته الرياضية الفكرية والعملية وصولا إلى بناء الإنسان والمجتمع ، ويطرح

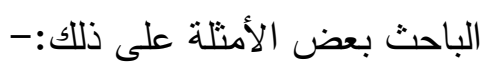
- أثنار في حياته الجامعية إلى واقع إهمال قيمة التربية الرياضية في فرنسا وأضاف إن ذلك يؤدي إلى الكسل الجسدي وعمل على تغيير فكرة أن الرياضة تقتل الدراسة، ولقد انتقد الثيوعيين في تركيزهم على الجانب التعليمي وإهمالهم لدور

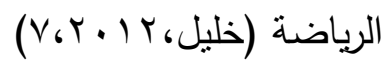
كما يذكر دي كوبرتان عن لعب التلاميذ الفرنسيين إذ يقول: ((إن تلاميذنا لا يلعبون لأننا لم نوجد لهم الألعاب

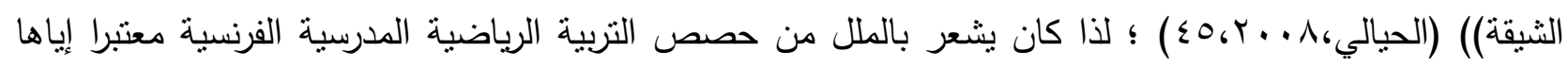
تعبيرا عن فثل المنهج التربوي السائد آنذاك وعقمه الواضح ، فمال للتنقيب عما يدخل عنصر المتعة في الرياضة فاستلهم بعد قراءات بالمناهج الإنكليزية وتأثره بالمعلم توماس ارنولد صاحب المقدرة على بث الفرح والبشاشة التي كانت

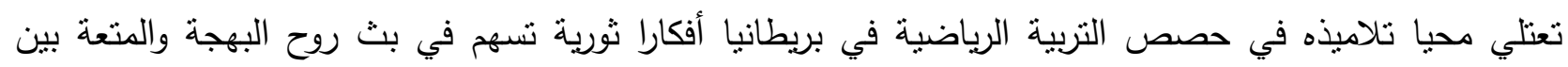

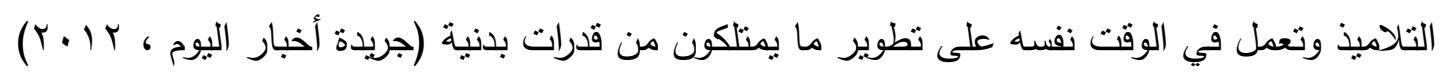
- تابع الأحداث الاجتماعية والصراعات السياسية وتعامل معها بنجاح ومثال ذلك نجاحه في تخفيف حدة التوتر بين

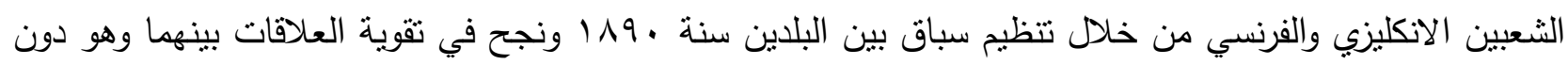

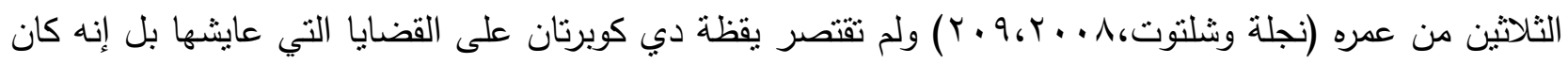

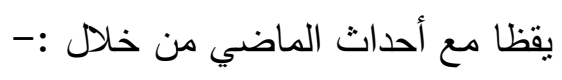
- - دراسة التاريخ اليوناني واستتباطه للأفكار والرؤى الإيجابية فيه. - تفتحت عينا دي كوبرتان أكثر تجاه حضارة الإغريق من خلال تنظظه ومتابعته لنتائج البعثة الألمانية للتنقيب في

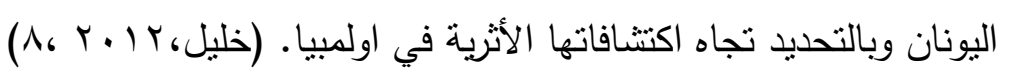

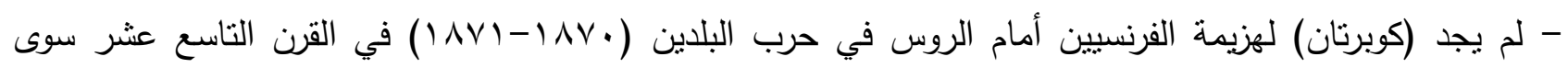
الضعف البدني لدى الثباب الفرنسي مقارنة بصلابة رجال الدولة القيصرية آنذاك لذلك لم تكن الاعتبارات الإستراتيجية

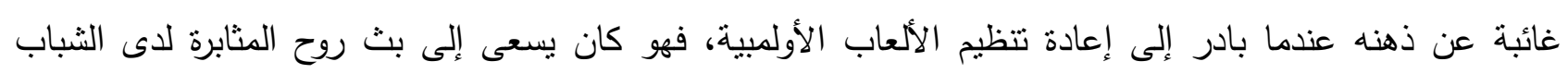




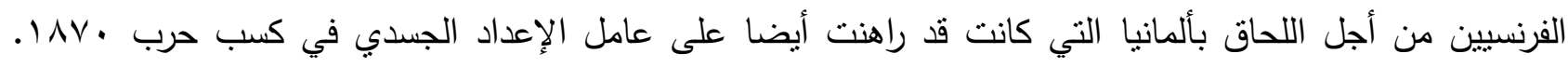

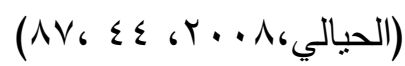
ويود الباحث أن يثير في نهاية هذا المبحث أن دي كوبرتان أمتلك يقظة ذات أبعاد قيمية أصيلة فكان يؤمن بأن أهم الأبه

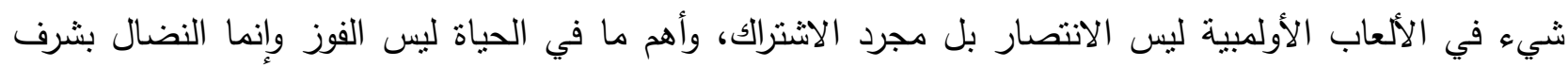

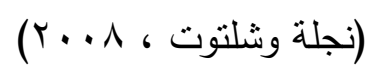

ـ- 1-7 مؤهلات دي كوبرتان العلمية

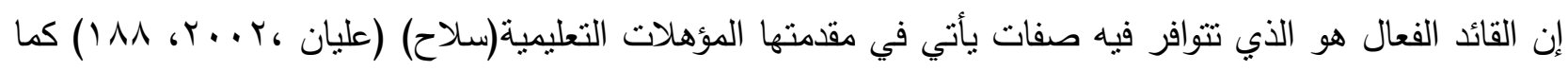

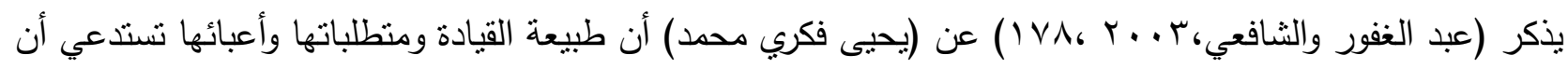

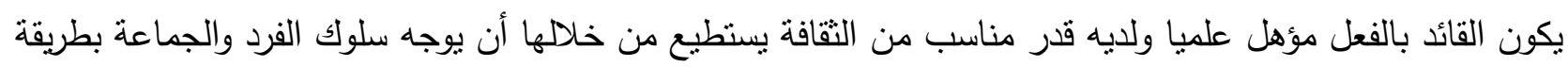

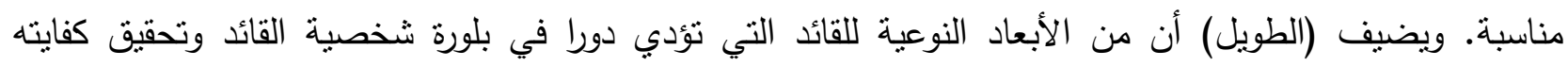

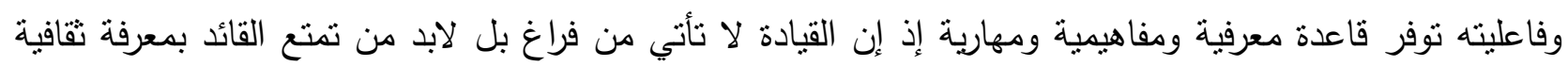

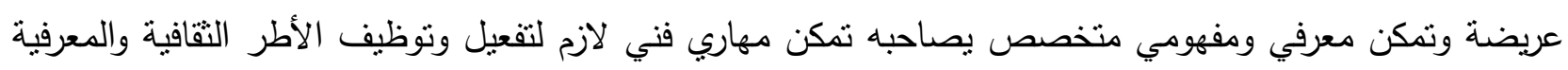

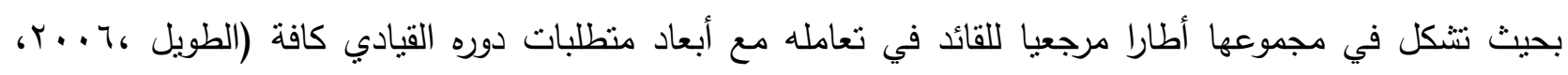

بناءٌ على ما سبق ومن خلال إطلاع الباحث على المصادر المتوفرة بعتقد أن التأهيل العلمي لدى كوبرتان يمر بثلاثة

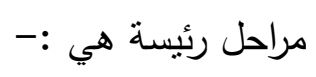

- مرحلة طفولته ونشأته إذ إن البارون دي كوبرتان ابن عائلة نبيلة من فرنسا تقوم على تدريس التربية وعلم النفس فئس

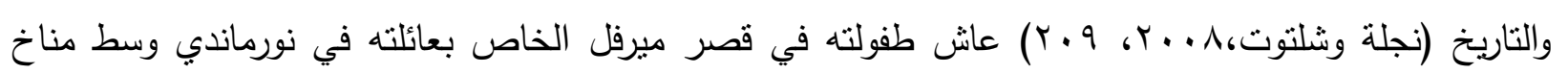

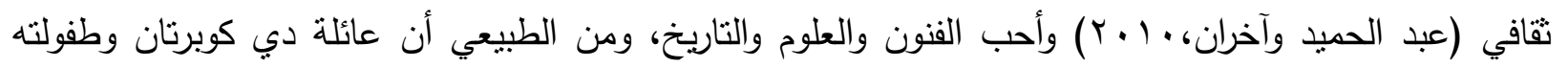

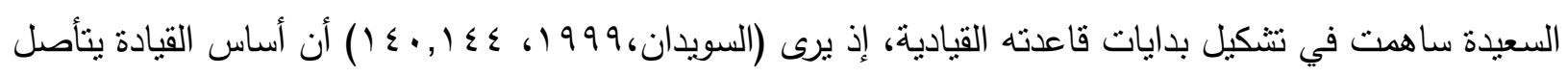

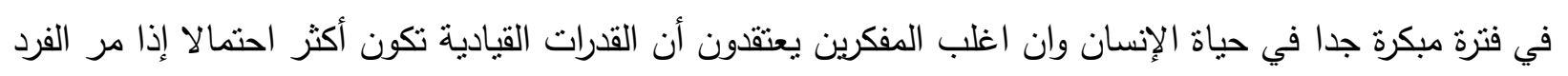

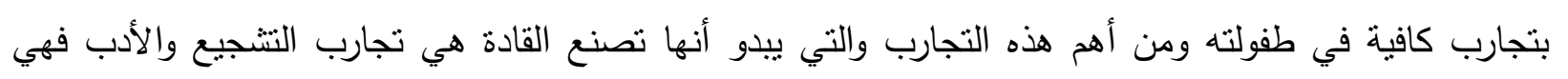

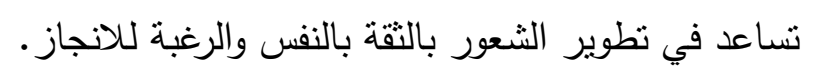

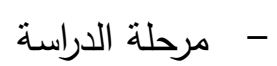

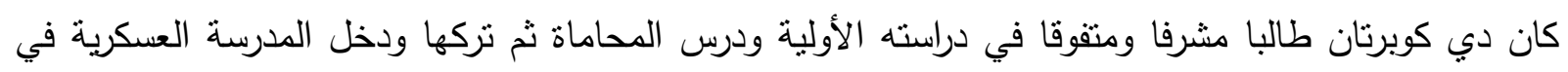

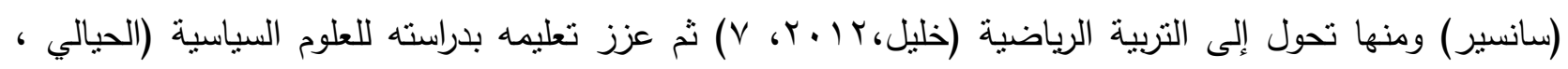

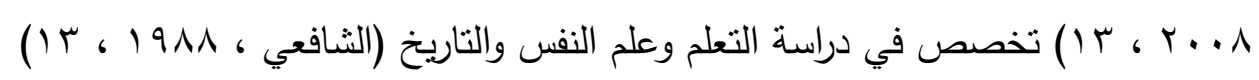
- مرحلة تطوره العلمي وتتكلت من خلال الإفادات والمؤتمرات العلمية، فضلاً عن اطلاعه ودراسته، ومن أمثلته ذللك:-

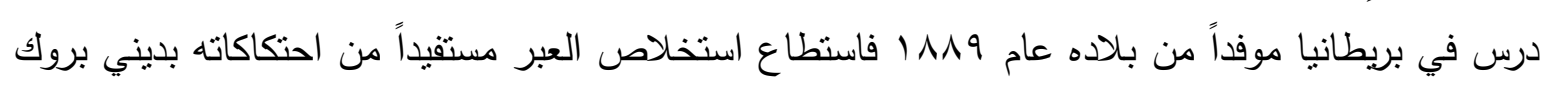

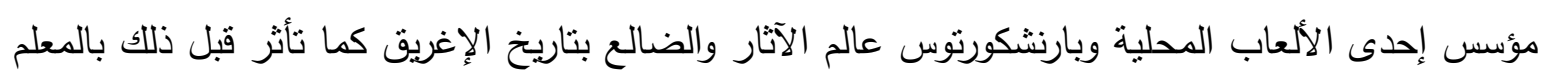

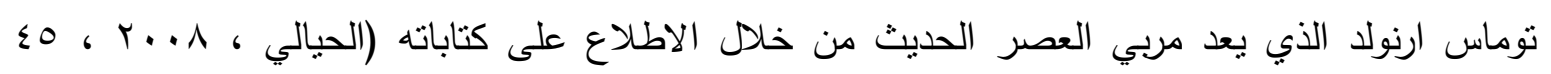

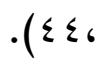
حضور مؤتمر بوسطن للتربية وزياراته الميدانية والرياضية للمدارس والجامعات في الولايات المتحدة وكندا

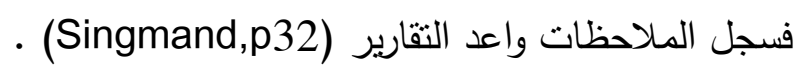


تفحص في تعليم الأطفال الألمان والبريطانيين والأمريكيين واستتنج بأن التمارين الرياضية هي التي تكون شخصاً ذا نشاط وحيوية (Britannica.com). أجرى دراسة على التربية الانكليزية لغرض الإفادة من تجاربها في هذا المجال وتطبيقاتها في فرنسا لتطوير وتحسين النظام التربوي الفرنسي، فاكتثف من خلال هذه الدراسة أن المشاركات والمساهمات الدولية في

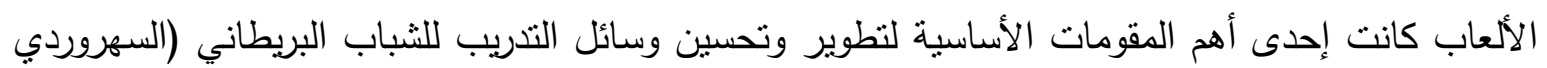
.) (11. ، 191. ، هاطلاعه وتأثره ببعض المحاولات الرياضية داخل بريطانيا مثل نتظيم العاب اولمبية داخل بريطانيا منذ سنة

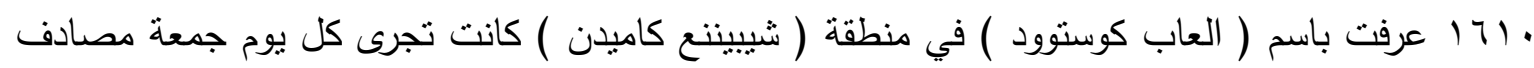

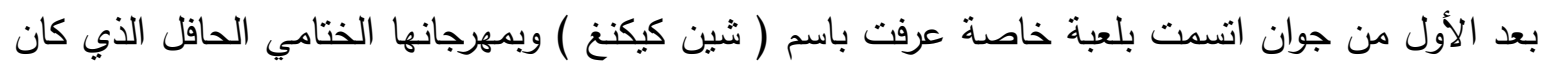

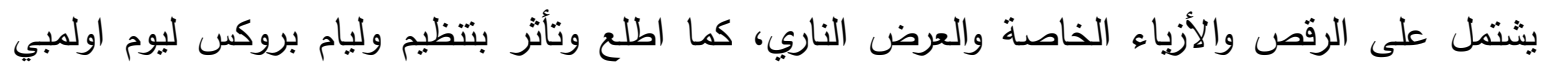

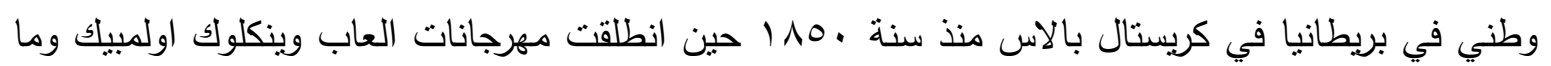

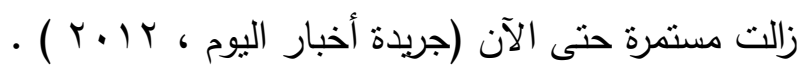

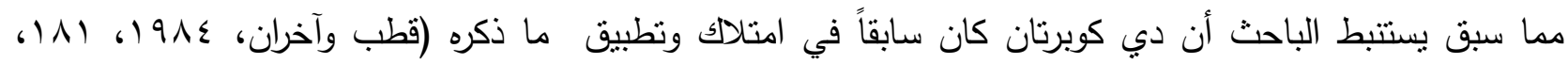

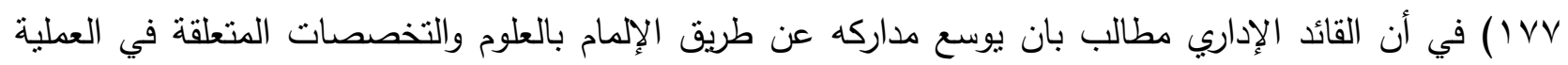

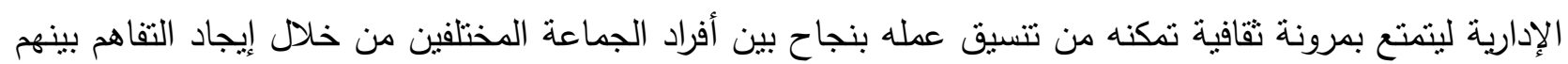
وتحقيق نرابط الجماعة وتماسكها.

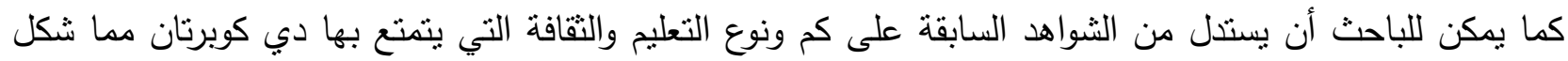
إحدى المقومات الأساسية للقيادة الاولمبية، إذ انه كلما كانت الحصيلة الثقافية والأكاديمية لدى القائد مرتفعة كلما

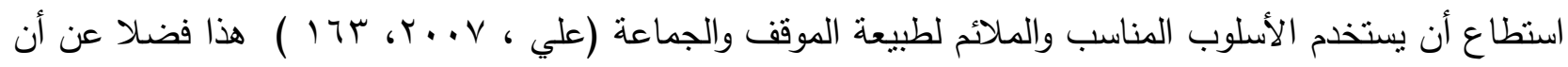

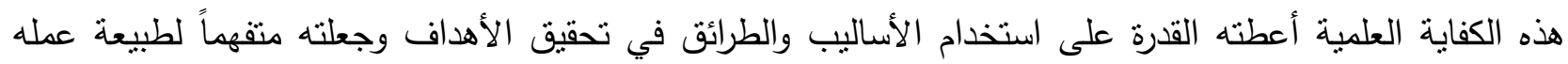

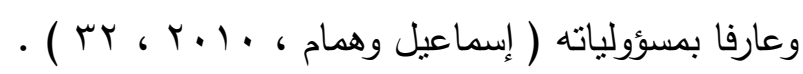

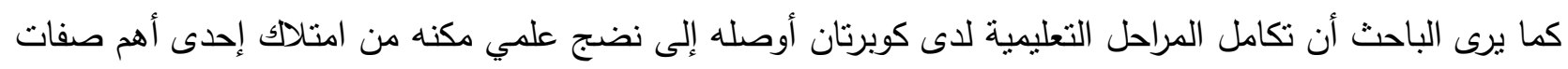

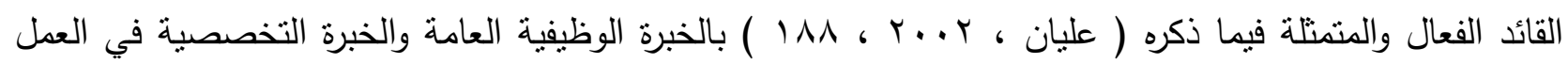

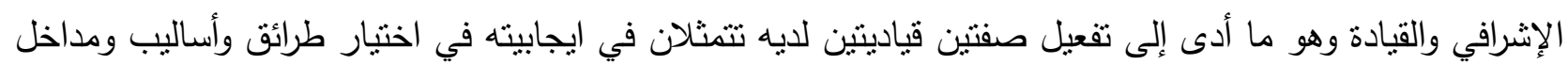

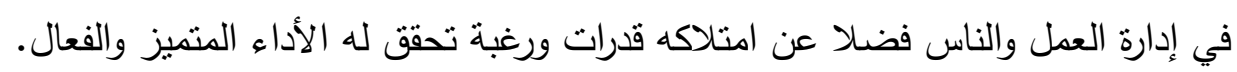

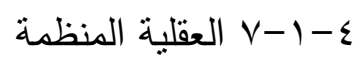

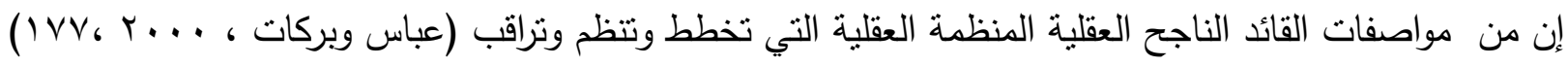

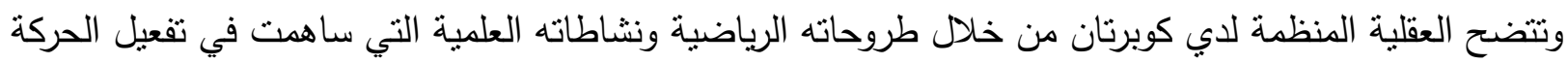

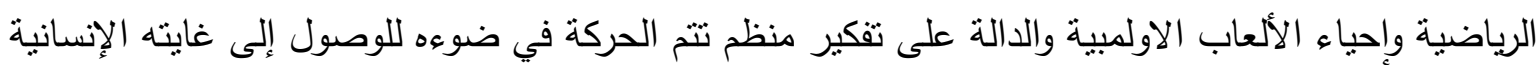

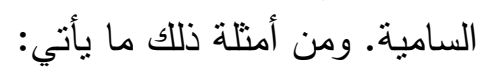
- بنى الثاب الفرنسي (دي كوبرتان) تحركه الإنساني من رحم المفهوم الصافي للتربية كمسألة أساسية من خلال

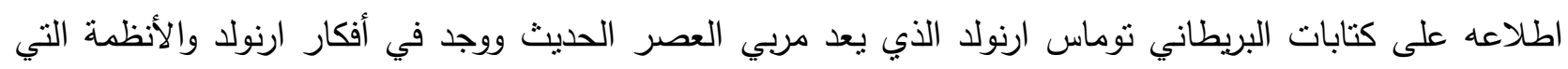

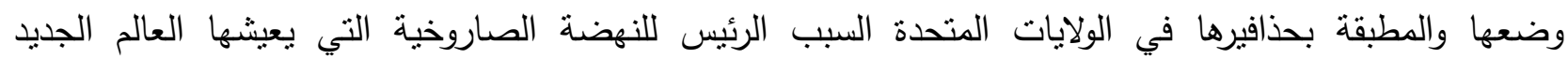
www.alkass.net. 
- وجد في التربية والتعليم الحقل المناسب لإعداد قياديين وكوادر قادرة على الإمساك بزمام الأمور . www.alkass.net

- نظم الندوات والمحاضرات لدعم فكرة الحركة الرياضية في المدارس والجامعات، كما نظم المؤتمر الأول للتربية البدنية والمنافسات المدرسية وقد لاقت أفكاره الرواج تدريجيا ولاسيما بعد دعمها بإسهاماته الصحفية في يومية لوفرانسية

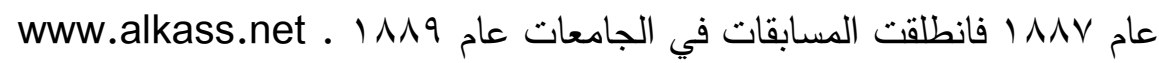
- هكذا بدء بنشر الرياضة والألعاب في فرنسا، ولما كان كوبرتان مسؤولا عن تتظيم وادارة جمعية الرياضة والألعاب

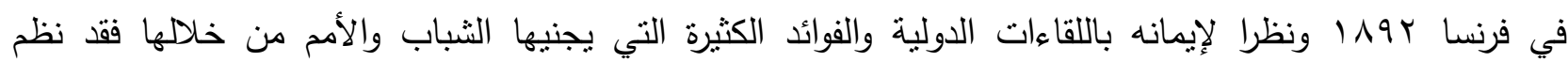

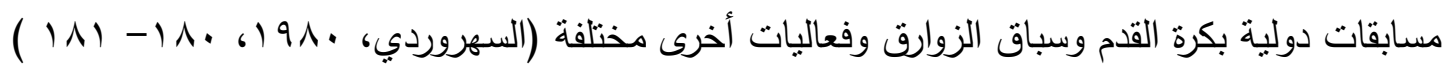

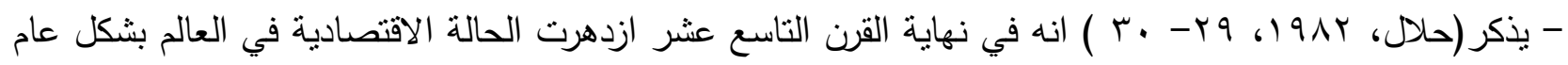
وانتشرت الثقافة وتوسعت العلاقات الدولية بين مجتمعات هذا الازدهار انعكس بدوره على الحركة الرياضية العالمية بإقامة المباريات الدولية الرياضية حيث جمعت رياضيين من دول مختلفة وتماشيا مع إقامة هذه المباريات الدولية كان لابد من إنشاء تنظيم لإدارة هذه الألعاب، وفي هذه الظروف المناسبة قام المربي الفرنسي الثاب بييرديكوبرنان واقترح

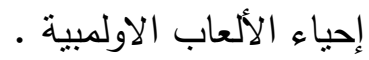
- - ولتنفيذ رؤيته في استئناف الألعاب الاولمبية الحديثة اوجد (دي كوبرتان) اللجنة الاولمبية الدولية كما انه اقترح أن

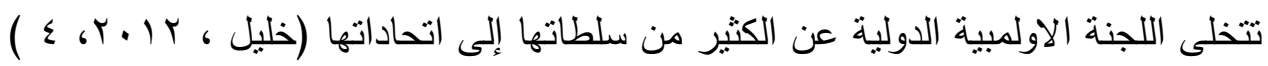
- سطر قائمة تضم أسماء قادة الرياضة البارزين في إنحاء في العالم طالبا معونتهم ومعاونتهم فكريا ومعنويا لإعادة

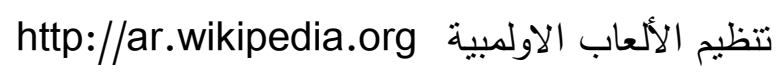

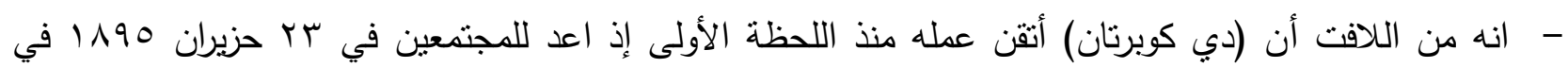

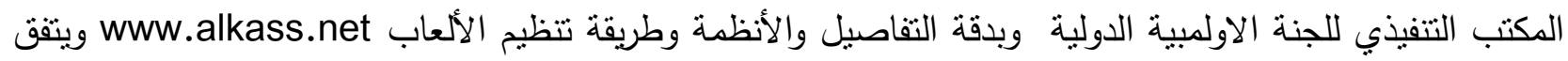
هذا مع ما ذكره (الثافعي، 1911 ، بال) في إن اللجنة الاولمبية الدولية قررت أن يكون برنامج الدورة الاولمبية

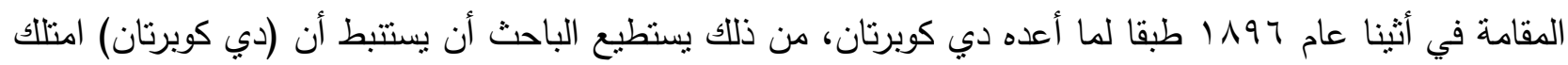

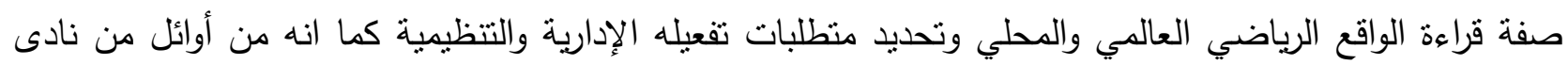
بتفوبض السلطة بالمجال الإداري الرياضي . وبناءً على ما سبق من أحداث وتحليلات فان (دي كوبرتان) يمتلك إحدى أهم صفات القائد الفعال والتي أثنار إليها

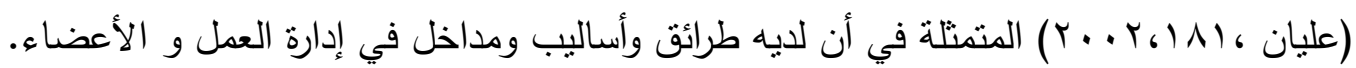

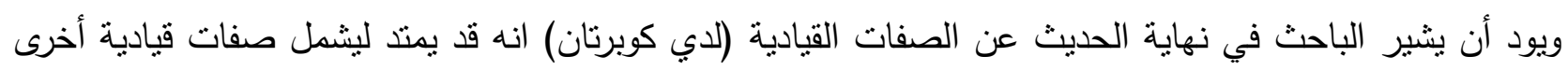
متداخلة أو منفصلة عن التي تم تتاولها ذلك لان أحداث حياته مليئة بالحركة الإداربة والقابلية القيادية. ع - خ خصائص القيادة الرياضية عند دي كوبرتان

سيتطرق الباحث في هذا المبحث إلى الخصائص التي أهلت دي كوبرتان لقيادة الحركة الاولمبية من منطلق خصائص

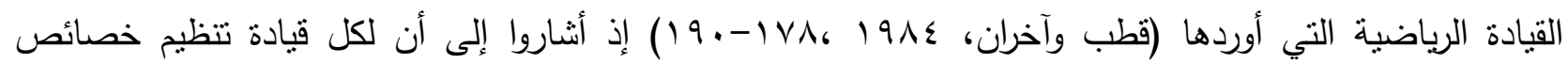
وسمات ذاتية تتعلق بطبيعة المهام وظروف الفعاليات التي تمارسها ونوع الأهداف المرسومة وغير ذلك من الأسباب

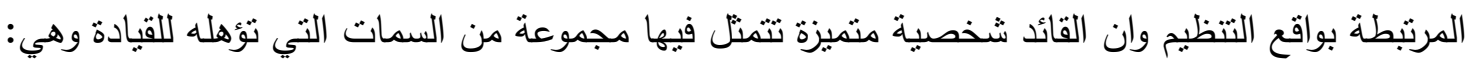


إذا إن من أولى مسلمات خصائص القيادة الإمام بطبيعة العمل التتظيمي وقد بين الباحث كيف تشكلت خبرة دي كوبرتان من خلال تعليمه ودراساته و اطلاعاته وزياراته العلمية وحضور المؤتمرات والندوات وإلقاء المحاضرات، وهو

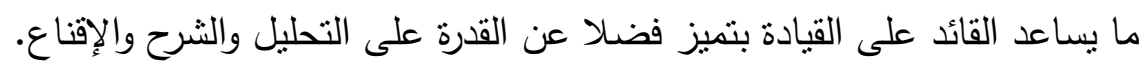
ع-r-r

التضحية بمعنى رغبة القائد في نسخير جميع إمكانياته لصالح المهمة ،فهو كما وضح الباحث ضحى بجهده ووقته للعمل الرياضي الاولمبي على وفق إرادة ورغبة ودوافع ذاتية، إما إنكار الذات فتعني تجاوز القائد لمصالحه الثخصية وحب الذات والأنانية، وتظهر هذه الخاصية القيادية عند دي كوبرثان بتجاوز تفكيره بذاته إلى التفكير بحياة وسلامة الآخرين ورفاهيتهم وتألفهم وتبادلهم المحبة وهذا لم يقتصر على مجتمعه الفرنسي بل تعداه إلى المجتمع العالمي. ع-r-r القدرة على التصور هي حصيلة مجموعة القدرات الذهنية التي صقلتها التجربة والمعرفة ومنها القدرة على الفهم والتذكر وربط الحقائق والظواهر بعضها ببعض والقدرة على التفكير بأسلوب علمي يوازن بين العناصر ويستتبط الحقائق ويسخرها لحل المشكلات، وتبرز هذه الخاصية عند دي كوبرتان من خلال عدة مواقف اهمها تصوره السليم في امكانية ان تكون بلني

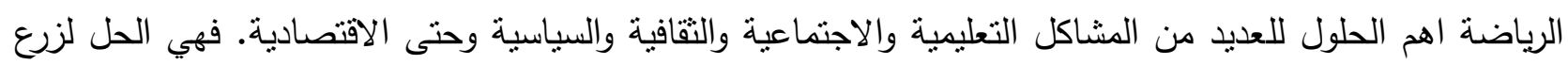
السلام والمحبة بين شعوب ودول العالم فضلاً من انها تبني الانسان والمجتمعات من خلال الجسم السليم والنشاط والحيوبة.

ع-r

يقصد بها السلوكية التي من خلالها يمارس القائد عمله ومن سماتها الأساسية : - التمسك بالأخلاق: تظهر هذه الخاصية جليا عند دي كوبرتان، إذ يذكر أن الثيء الوحيد الذي أراد نقله من العصور الكلاسيكية إلى العصر الحديث كان قيمها الأخلاقية كالشرف والاحترام والعدل والتفوق (جريدة أخبار اليوم

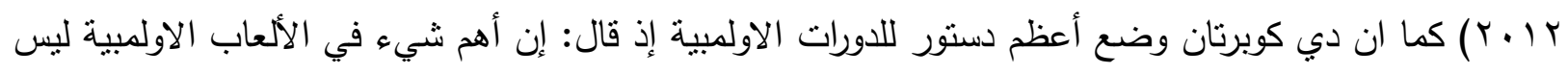

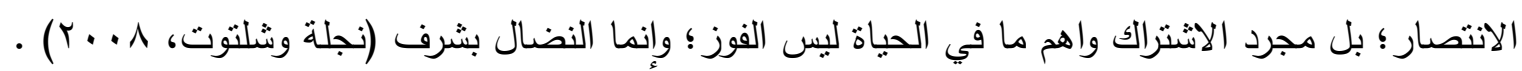

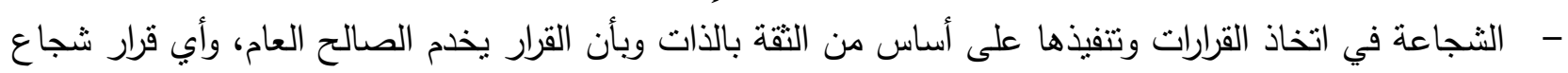
ذاك المتعلق بإحياء الألعاب الاولمبية.

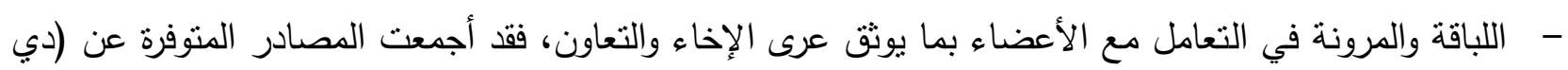

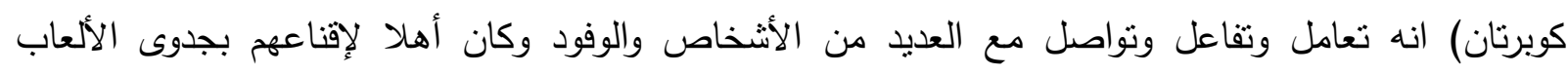

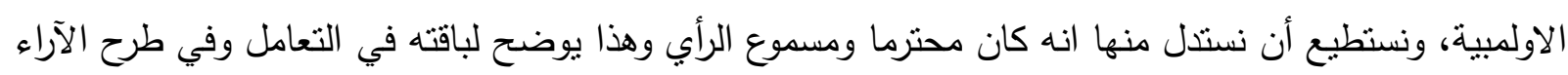

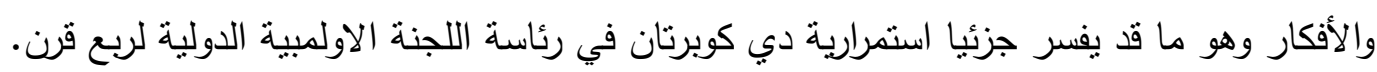

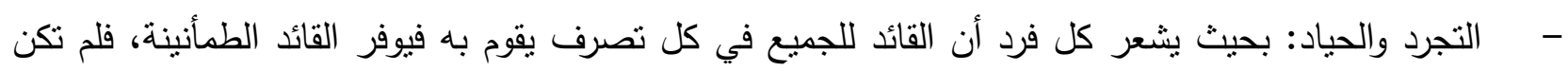

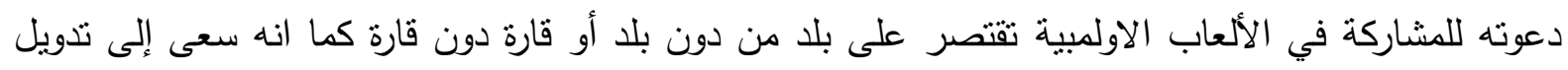

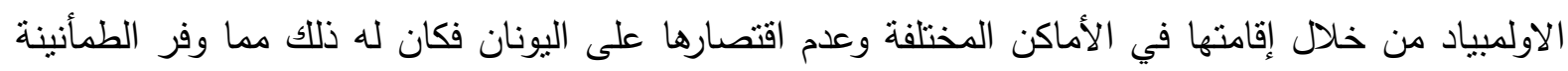
تجاه تصرفاته الحيادية التي تأكدت أكثر من خلال اختياره لمدينة لوزان السويسرية مقر رئيس للجنة الاولمبية

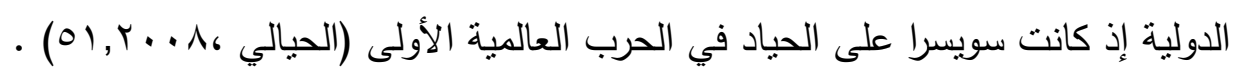




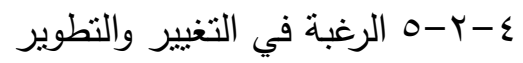

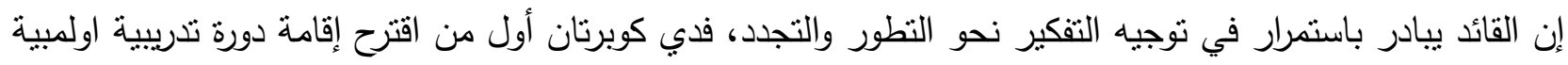

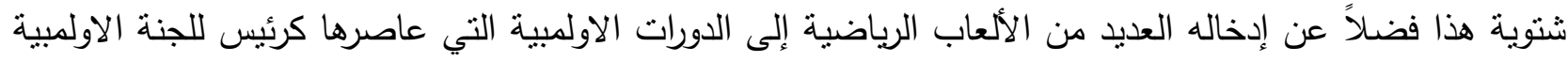
الدولية.

ع-r الصلاحية القيادية لاى كوبرتان

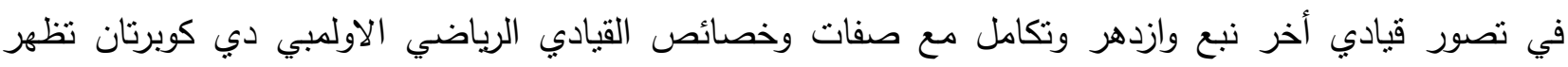

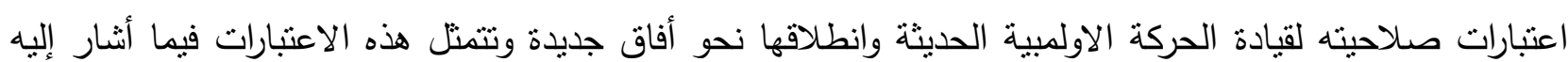

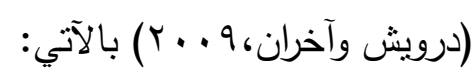
ع-r-1 الإيمان بالهدف فالإيمان بالعمل وبجدواه يأني في مقدمة المقومات القيادية، فالإيمان باعث على الحماسة كما انه يولد طاقة كبيرة وعزيمة متجددة ويجعل الفرد يكرس حياته للعمل ويقوده إلى الابتكار. ع-ب-r و القيادة للأمام تعني إمكانية القائد لتتكيل المستقبل والحياة على وفق أرادة لتحريك منظمته للأمام وجعل يوم المنظمة أفضل من أمسها وغدها أفضل من يومها. ع-r-r نفاذ البصيرة رؤية ما يمكن أن يكون عليه مستقبل المنظمة وعمل تقدير سليم لذلك.

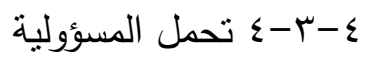
فالقائد الحق هو الذي يرقى بفكره إلى مسنوى عال من تقدير المسؤولية وخوض التجارب والأقدام على العمل الذي

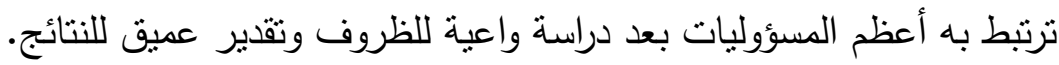

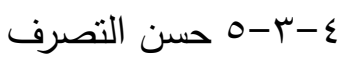
تتجلى الحاجة إلى القيادة الرشيدة عندما تسوء الأمور بفعل الأزمات أو الظروف القاسية وليس المطلوب هنا هو مجرد

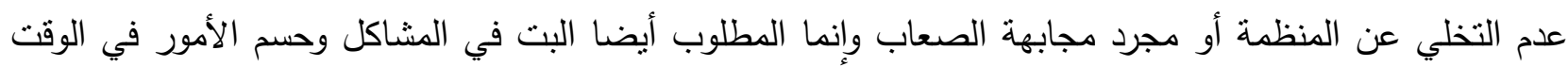

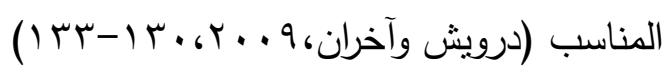
ويرى الباحث أن دي كوبرتان تمكن قبل قرن من تفعيل وتوظيف هذه الاعتبارات للصلاحية القيادية فهو بحق رجل

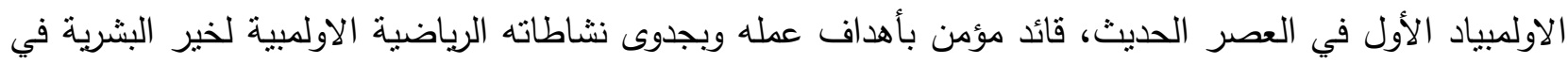

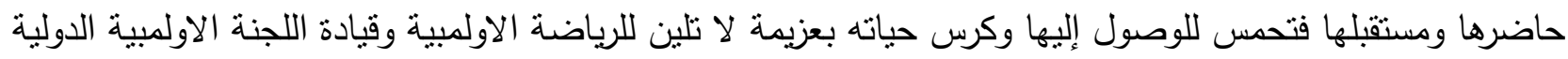

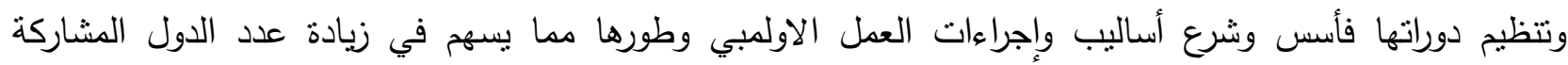
واللاعبين وعدد الألعاب من دورة إلى أخرى.

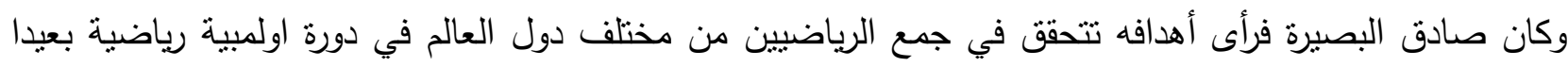
عن التعصب والبغضاء والحروب والمشاحنات على اختلاف أنواعها وجعل الرياضة الاولمبية خيمة تجمعهم اللسلام والمحبة فضلا عن المشاركة والتتافس الشريف.

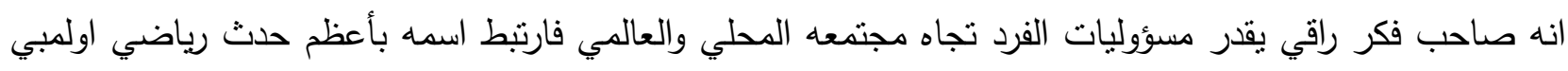

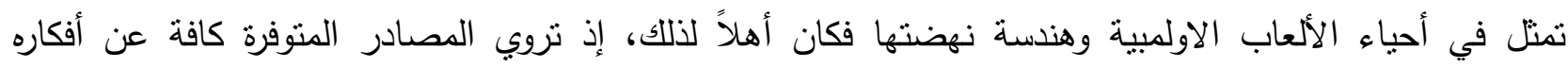

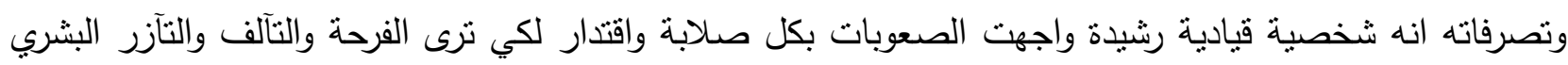
فكان لها شرف تحقيق ذللك بلا مبالغة ولا منازع لأنها كانت صادقة النات النوايا وامتلكت فطرية حب الإنسان لأخيه الإنسان. 
ع - ف فلسفة دي كوبرتان الرياضية وانعكاساتها القيادية

إن (دي كوبرتان) صاحب بصمة فلسفية في التربية الرياضية ذات رؤى تحمل في طياتها معاني كثيرة لضرورات الحياة الإنسانية السليمة والسلمية لذلك حققت فلسفته العالمية في كامل أبعادها ولم يعترض عليها أو يشكك فيها احد دئ دئه وتسابقت دول العالم حكومات وشعوبا ترغب في الانضمام للحركة الاولمبية بكامل شروطها من دون تعديل بلاءم طبيعتها

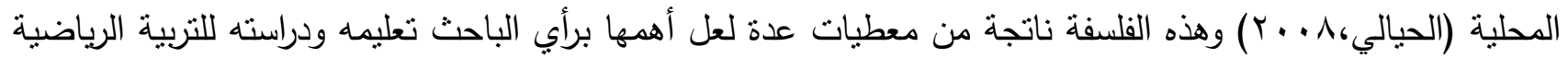

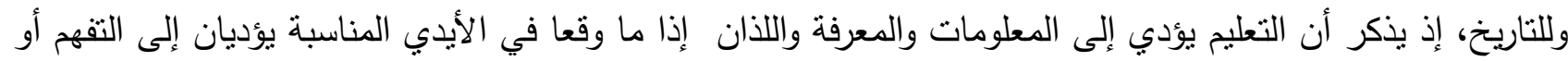

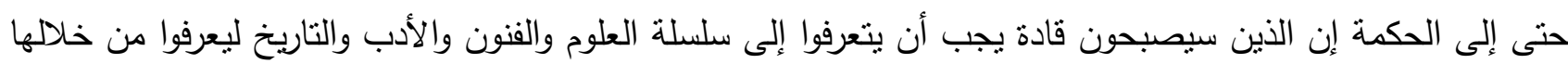

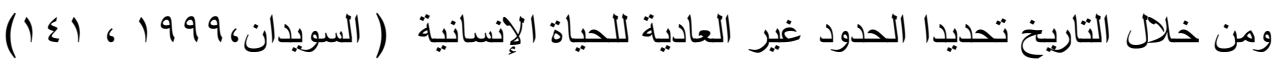
انه أنموذج شفاف وواضح ورائع للتعريف الفلسفي ومخرجاته، فالفلسفة كما يذكر (الطويل) إن توضح وتناقش القيم

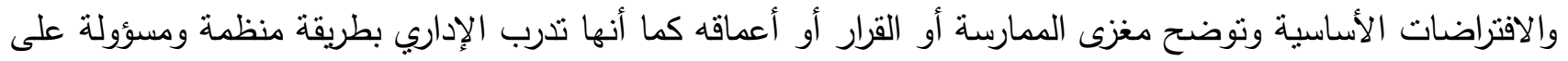

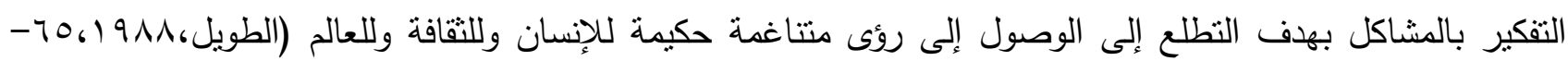

ومن المعطيات الفلسفية التي امن بها دي كوبرتان، والتي توافقت مع التوجهات الفلسفية التربوية التي نادى بها الفلاسفة من

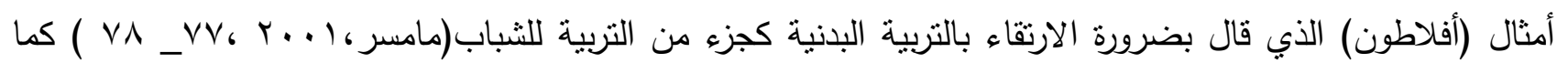
أنها تطابقت مع جانبين أساسيين من جوانب فلسفة التربية الرياضية واللذان يذكرهما (السراج) بجعل المجنمع عارفاً وعالماً بأن التربية الرباضية تسهم إسهاماً فعالاً في ترسيخ القيم الأخلاقية الحميدة فضلاً عن القيام بتوضيح العلاقة بين التربية

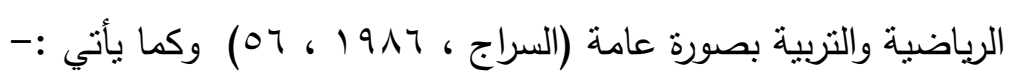

- إن الدراسة والرياضة يجب أن نكون في متتاول الجميع وأنثار في أفكاره عن التربية الرياضية وضرورتها في في المدارس واعتمادها في المناهج الدراسية لتنشئة الجسد والعقل معان وان وان أفضل طريقة لتطوير عقول الثباب

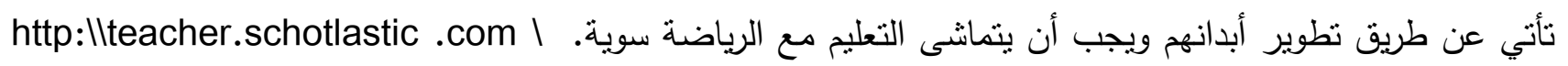
activites games $\backslash$ modern .htm

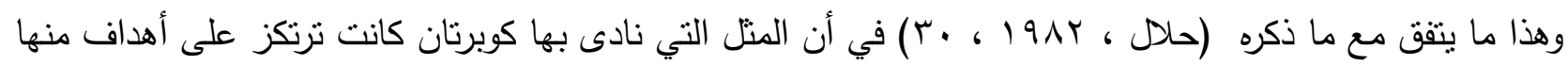
محاولة تطوير وتحسين الإنسان بالرقي فيه ليس فقط عقلياً وأخلاقياً؛ بل وجسدياً.

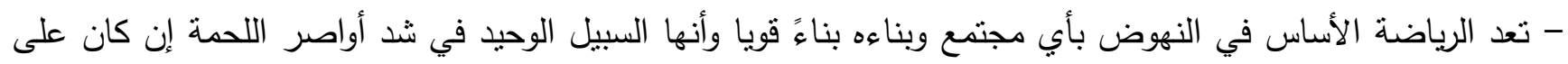
نطاق بيئة صغيرة أو على نطاق عالمي وأن للرياضة ادوار شتى أبرزها تكوين مجتمع رياضي ولئي صالح وسليم (جريدة

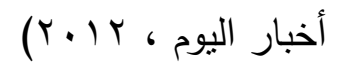

- لفت أنظار العالم إلى حقيقة أن أب برنامج أهلي للتربية البدنية والمنافسة الرياضية لن تقتصر فائدته على تربية شبان وشابات أقوى بنية وأحسن صحة بل أنها تخلق مواطنين أفضل وأكثر سعادة عن طريق بناء الثخصية (الثافعي ،

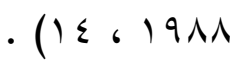
- إن ممارسة الرياضة وسيلة لتكامل الفرد وليست غاية، فالهدف من الرياضة هو إعداد الفرد بدنيا ونفسيا مما يؤدي إلى

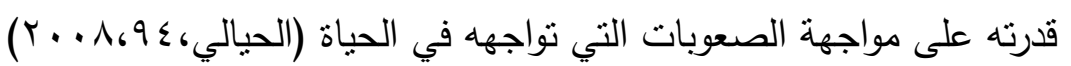
- حدد أهدافا للدورات الاولمبية تتمثل في الارتقاء بالمستوى البدني والأخلاقي بوصفها القاعدة الأساسية للرياضة وتهذيب الروح الرياضية للشباب والمساعدة على نشر السلام في جميع أنحاء العالم وتوطيد العلاقات بين مختلف شباب العالم في

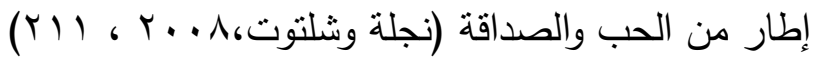


- رأى أن الدورات الاولمبية تجعل شباب العالم يجتمعون في حب وسلام على مائدة الرياضة بعيدا عن السياسة والحروب

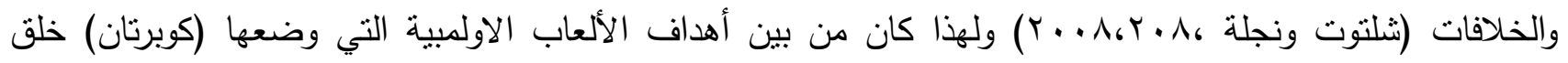

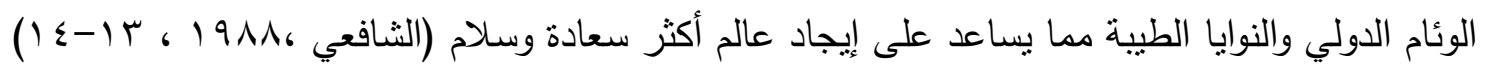

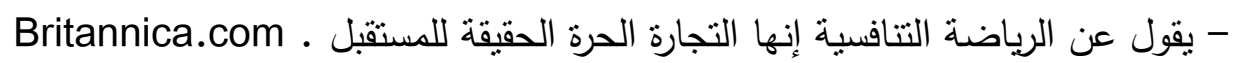
- إن الألوان الستة للعلم الاولمبي المترابطة هكذا تمثل كل الشعوب بدون استثاء وهذا هو الثعار العالمي الحقيقي . http://www.chevroncars.com إن دي كوبرتان بما حمله من أفكار وفلسفة رياضية أتت أكلها بما بذله من جهود لتطبيقها واستطاع تفعيل الترابط الذي أثنار إليه (الطويل) في أن العلاقة بين الفلسفة والإدارة تكمن في التصور المشكل للعلاقة بين النظري والعملي وهي من المشكلات العملية الأساسية في الحياة وذلك لارتباطها بسؤال يتعلق بكيفية تأثنر كل من الذكاء والتبصر على التى العمل والممارسة ،وكيف يمكن للعمل أن يجني ثمرات التبصر الزائد في المعنى، ومن ثم تكوين روئة واضحة للقيم "الجيدة " المفيدة وللوسائل التي يمكن أن تيسر تجسدها في الخبرة ولا جدال في أن الإداري التربوي المؤهل والمتمتع بروئية فلسفية

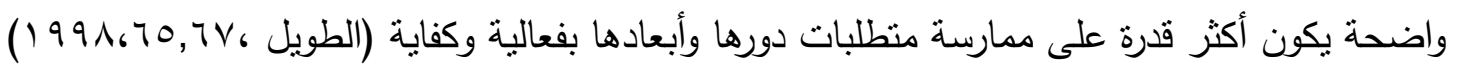

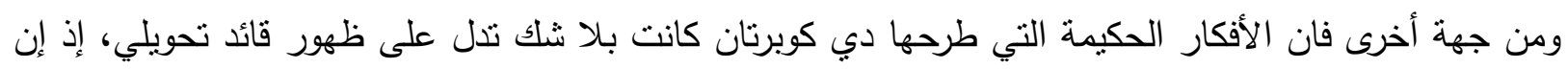
القيادة التحويلية كما تذكر (الغزو) لها رؤية مستقبلية ثاقبة وتحدث تغيرات جوهرية وجذرية وتهنت بالقيم التقافية

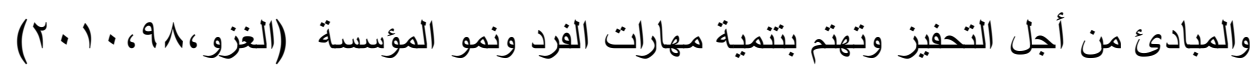
كما أن هذه الفلسفة الرياضية وتطبيقاتها ندل بصدق على توافر ابرز ملامح قادة المستقبل في (دي كوبرتان)

$$
\text { ا والتي أثنار إليها (العدلوني) متضمنة الآتي:- }
$$

r- يشعر أن وظيفته هي نقل الناس من حوله نقلة وصلة حضارية.

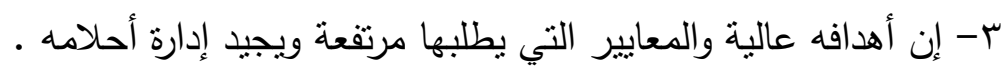
ع - يتمتع بثقة ذاتية عالية وبالتفاؤل والأمل والحياة. 0- يتمتع بحضور بدني ديناميكي ونشاط واضح وممارسة غير محدودة .

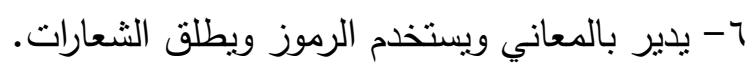
- يحب العلم. - - V

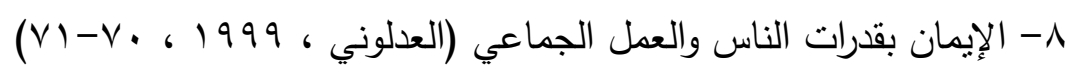
من النتائج والتحليلات السابقة يستطيع الباحث أن يؤكد تحقق فرضا البحث من خلال امتلاك البارون الفرنسي (دي كوبرتان) صفات وخصائص واعتبارات الصلاحية القيادية وفلسفة في التربية الرباضية والاولمبية أهلته لإحياء الألعاب الاولمبية وإدارة تطويرها والقيام بدوره القيادي الرياضي والاولمبي واتبات بفاعلية. ه- الاستتناجات والتوصيات 0-1 الاستنتاجات ا- امتلاك البارون الفرنسي (دي كوبرتان) تشكيلة قيادية فذة من صفات وخصائص واعتبارات أهلته بكل جدارة أن يكون صاحب الخطوة الإستراتيجية في إيقاد الثمعة الأولى للألعاب الاولمبية الحديثة كما مكنته من إدارة وتطوير الحركة الاولمبية الدولية بتمبز واقتدار . الإسطرة ץ- امتلاك دي كوبرتان فلسفة رياضية واولمبية سليمة وسلمية وشفافة جعلته أكثر قدرة على ممارسة منطلبات دوره القيادي الاولمبي بفاعلية. 
ז- إن المجال الرياضي يعد من المجالات الحياتية التي تستثمر وتعزز القدرات القيادية فضلا عن إظهارها كونه ميدان

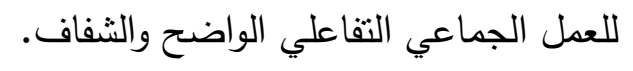
r- r r التوصيات

ا - اطلاع القيادات الرياضية العاملة على مضمون هذات البحت والثأمل في التيات السلوكيات والمقومات التي أدت إلى بلورة

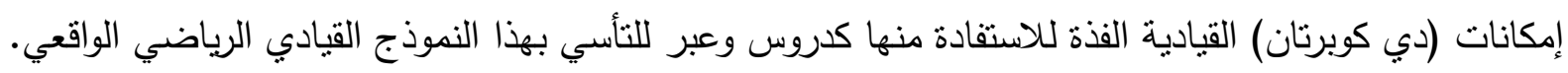

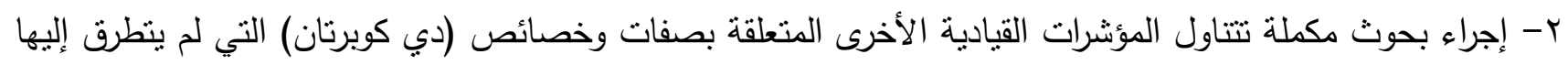
الباحث. ץ-إجراء بحوث مشابهة على القيادات الرياضية البارزة والمؤثرة في الحركة الرياضية سواء أكانت عالمية أم قارية أم عربية أم محلية.

\section{المصـــــادر}

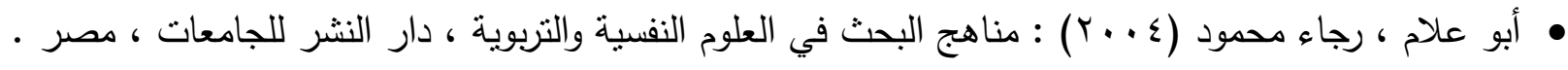

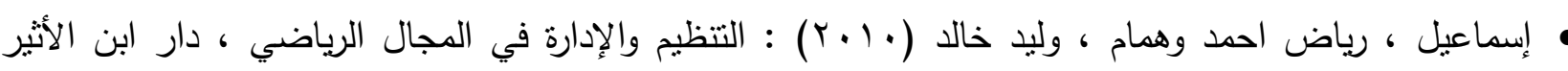

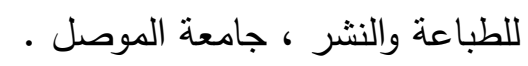

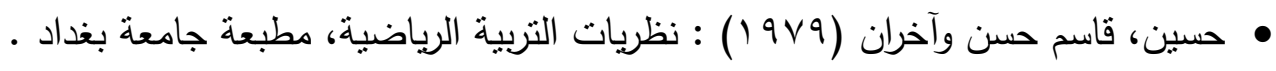

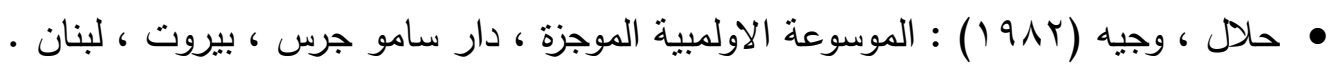

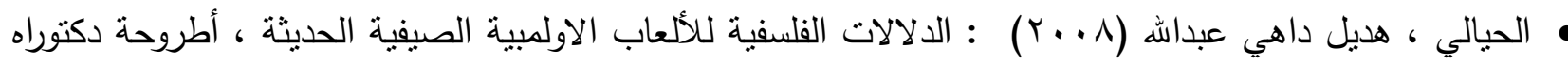

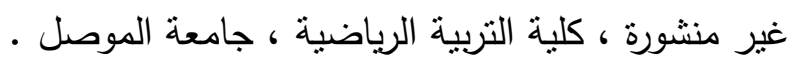

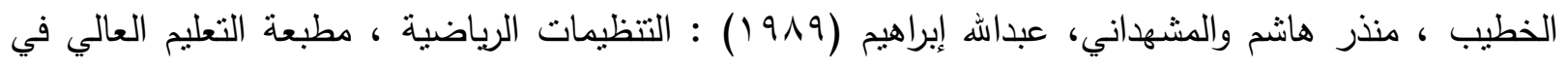

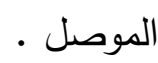

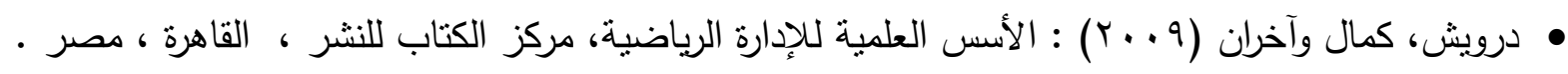

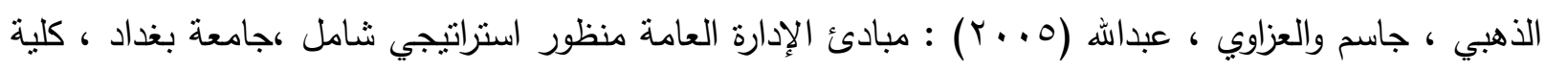

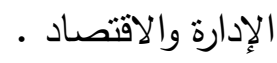

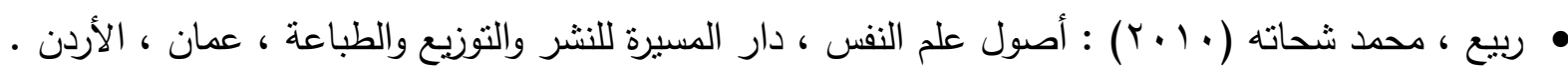

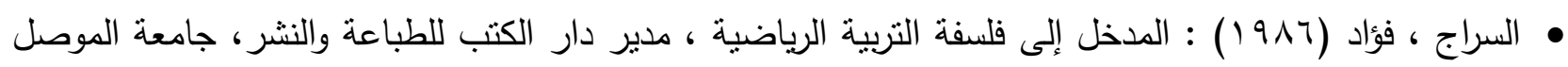
• السكارنة ، بلال خلف (• • ( ) : القيادات الإدارية الفعالة ، دار المسيرة للنشر والتوزيع والطباعة ، عمان ، الأردن • السهروردي ، نجم الدين (•191) : الموجز في فلسفة وتاريخ التربية الرياضية ، دار الكتب للطباعة والنشر ،

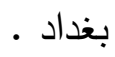
السويدان ، طارق محمد (1999) : القيادة في القرن الحادي والعشرين ، ج r r، خلاصة الفكر الغربي حول القيادة

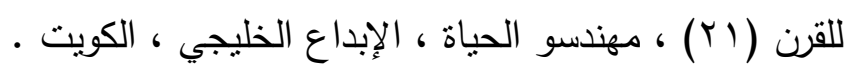

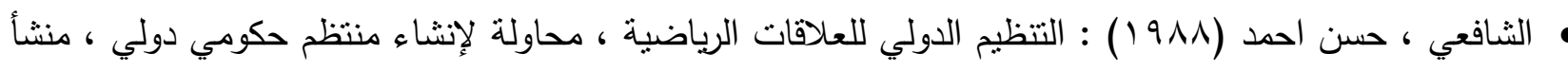

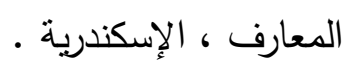

مثلتوت ، حسن معوض ، حسن سيد (r/911) : التتظيم الإدارة في التربية الرياضية ، دار المعارف ، القاهرة . 


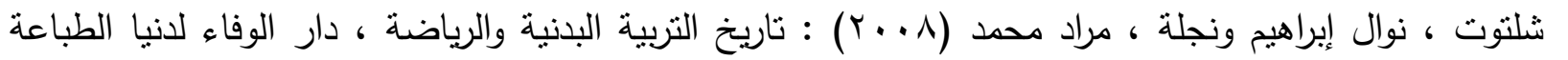

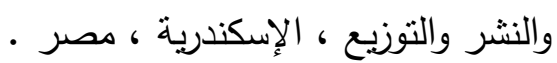

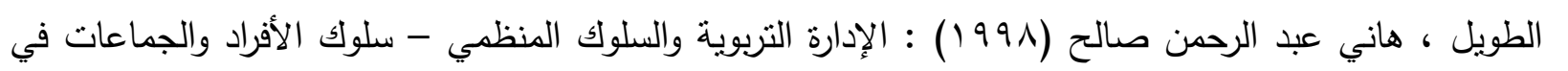

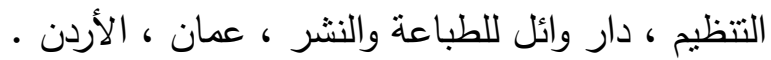

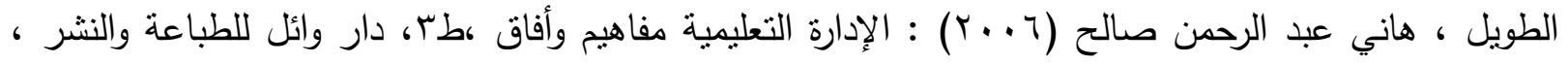

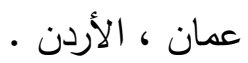

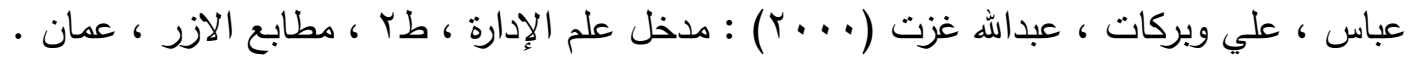

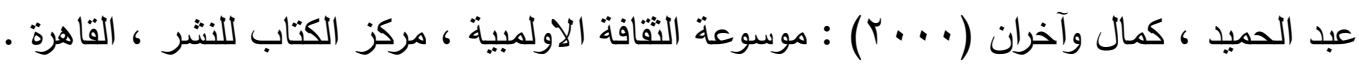

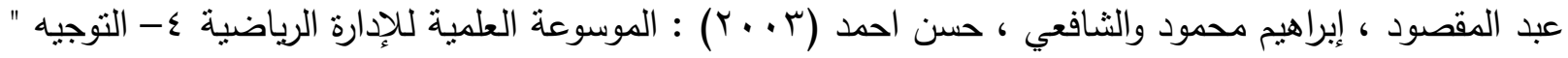

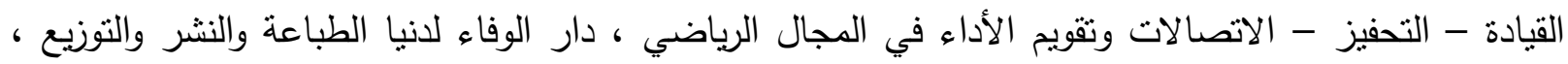

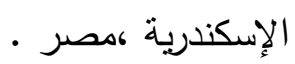

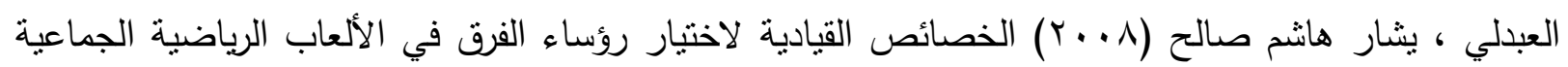
من وجهة نظر الددربين واللاعبين ، رسالة ماجستير غير منشورة ، قسم التربية الرياضية ، كلية التربية الأساسية ،

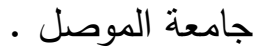
• العدلوني ، محمد أكرم (1999) : القيادة في القرن الحادي والعشرين ، ج)، القائد الفعال ، مهندو الحياة ،

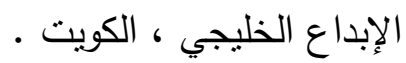
عريفج ، سامي (19Av (1): مناهج البحث العلمي وأساليبه، دار مجدلاوي للنشر ، الأردن.

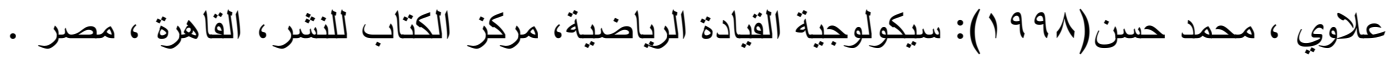

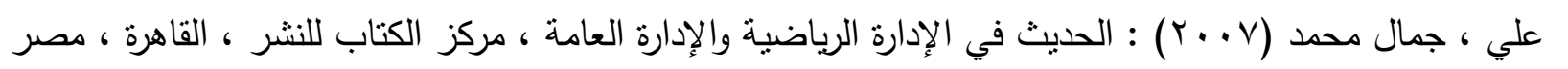

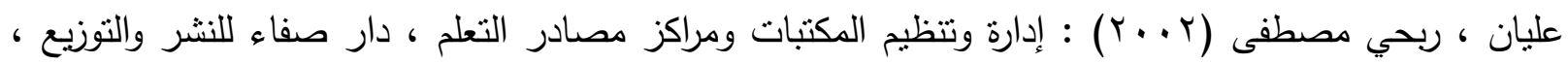

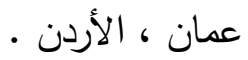

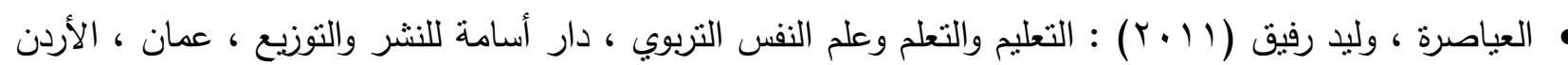

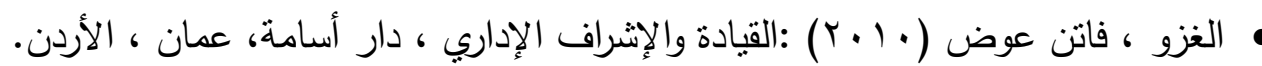

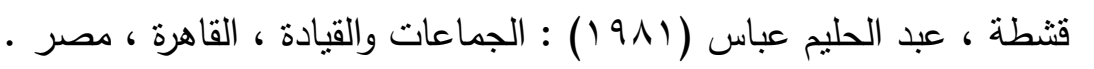

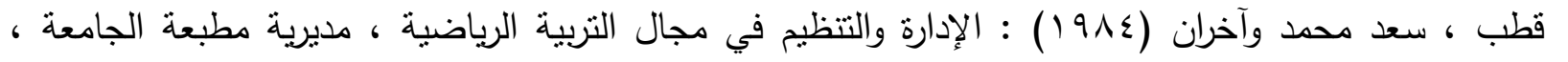

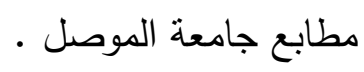
كلالدة ، ظاهر محمد (1991) : الاتجاهات الحديثة في القيادة الإدارية .

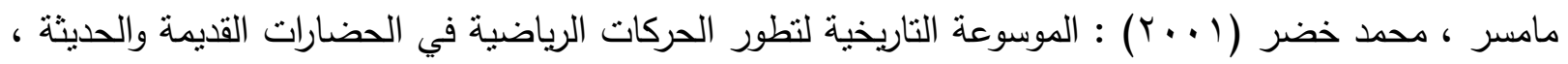

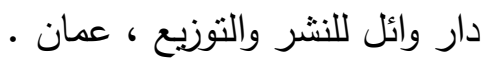
• محمد، شامل كامل وحسون، هيثم عبداله (.99 199) : قيادة الثعوب، مطابع التعليم العالي ، الموصل ، العراق .

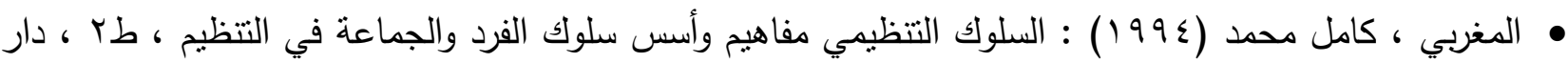

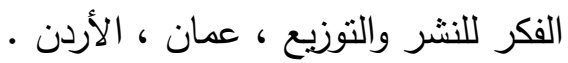




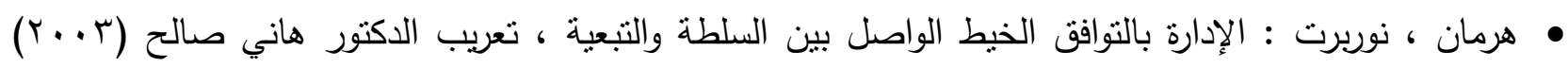
مكتبة العبيكان ، الرياض ، السعودية .

- Adams ,Lindsayw (2002) : The Olympic Games: Ancient and modern ,MA:pearson custompublishing, Boston .

- Browne ,Ferrigno\&Muth , R. (2004) Leandership mentoring in clinical practice : Role socialization, professional development, and capacity building . Educational Administration Quarterly , 40(4) , 468-494 .

- Games. Chicago: University of Illinois Press .

- Guttman, Allen(1992): The Olympics: A History of the Modren

- Sigmund Loland : critical Reflections on Olympic Ideology, cencre for Olympic studies The Norwegian state university for sport and phys, E.d.p26-45

- Kanin,David B. (1982) : A politival History of the Olympic Game.Boulder,CO : Westview Press.

- Tead,Ordway (1965) : Art of Leadership, New Yourk, McGraw Hill Book Company .

- Turban ,Efraim: Mclean , \&Wetherbe , James (2002) : Information teachnology for management : Trrans forming business in the digital firm $\left(3^{\text {rd }}\right)$. New Yourk, John wileg\& sons, Inc. .

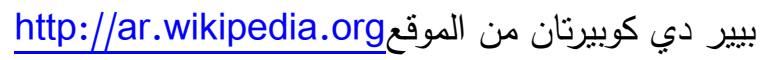

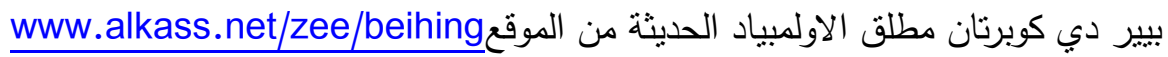

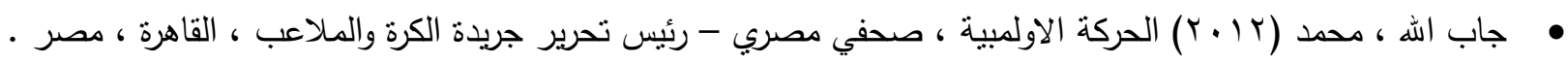

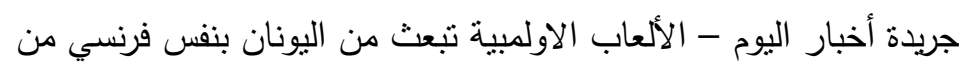

$$
\begin{aligned}
& \text { الموقعww.djazairess.comlakhbarelyoum }
\end{aligned}
$$

- Jennifer Rosenberg,About.com ,history of The Olympics Greating The modern Olympic Games

- Olympic Games" Britannica.com.Retrieved August 10, 2000 fromthe World Wide Web. (httpllwww.britannica.comlbcomleblarticlel2lo,5716,115022+1+108519,00.html)

- The modern Olympics

- http://www.chevroncars.com/learn/history/modern-oiympics

- The modern Olympic Games, From Grolier On line's-New Book ofknowledge. . scholastic .com/ activities /athens games/modern . htmhttp://teacher 